\title{
Concrete Partnership Accountability Standards
}

In Chapter 3, it was argued that accountability arrangements should depend on organisational function. In Chapter 4 , it was shown that depending on their main function, four different groups of partnerships can be distinguished. Which kind of accountability should each of these groups concentrate on? And which standards do partnerships need to live up to in order to create a sufficient level of accountability?

This chapter takes each functional group of partnerships in turn and establishes which accountability standards it, as well as other organisations with similar functions, should fulfil.

\subsection{Advocacy and awareness-raising partnerships: Basic standards for all partnerships}

The first group of partnerships identified above includes those whose main purpose is to promote certain issues through advocacy and awareness campaigns. Often, these partnerships also collect and disseminate relevant information and offer a platform for the coordination of the activities and programmes of members.

As indicated above, these partnerships only require basic forms of authority to operate. They are basic in the sense that they are a precondition for any partnership to work. Partnerships exercising functions other than advocacy and awareness raising demand other forms of authority in addition to this basic set. All partnerships should therefore comply with the accountability standards developed here for advocacy and awareness-raising partnerships, in addition to their more specific requirements. The common basis for all partnership types includes three forms of delegated or assumed authority.

Firstly, partnerships need the authority to exist and operate. Who grants this authority depends on the formal constitution of the partnership. Partnerships can be incorporated and have independent legal status. In this case, the country of incorporation determines the rules and conditions for registration. Most countries have stricter rules for organisations that are 
granted exemptions from taxes. ${ }^{1}$ Partnerships that are not incorporated as independent entities derive their authority to operate from their founding members and the institution(s) hosting the partnership secretariat. Thus the host organisation, often in cooperation with the founding partners, can determine which rules and procedures apply to the partnership.

Secondly, partnerships need to acquire authority over the necessary operational resources. For their financial needs they can rely on a variety of sources. Some draw on an initial endowment to support their ongoing activities, others use contributions from members, individual or institutional donations or, in rare exceptions, revenues from commercial engagements. In addition, partnerships often rely on volunteer staff time, as well as office space and equipment contributed by partner organisations.

Thirdly, partnerships require the support of partner organisations or members. Even where they do not contribute financial or other resources, partners are important because they express support for the partnership and its mission through their membership. This kind of support is especially important for advocacy and awareness-raising partnerships. Their members usually have to explicitly endorse the partnership's goals by signing up to its mission statement. The more individuals and organisations do so, the more forcefully an advocacy and awareness-raising partnership can promote its cause. Supportive partner or member organisations are also more likely to contribute relevant information to the partnership, to take up knowledge and information disseminated by the partnership and to accept the partnership's proposals for coordinating member activities.

As depicted in Figure 5.1, the basic forms of authority required by partnerships - the licence to operate, authority over operational resources and support by partner organisations - give rise to three basic forms of accountability. All types of partnerships should at a minimum be subject to procedures and mechanisms to ensure accountability for complying with relevant rules and regulations, to create financial accountability and to generate accountability for working towards the partnership's mission.

Many NGOs are functionally similar to advocacy and awareness-raising partnerships. While NGOs do engage in many different kinds of activities, ${ }^{2}$ advocacy and awareness raising as well as the collection and dissemination of information and the provision of platforms for coordination are often core components of NGO work. ${ }^{3}$ While developing concrete accountability standards for advocacy and awareness-raising partnerships, we can therefore draw on broadly accepted and established governance and accountability standards for NGOs.

\subsubsection{Accountability for complying with relevant rules and regulations}

Rules are designed to regulate behaviour. They serve to prevent individuals and organisations from abusing their authority and violating the rights of others. 


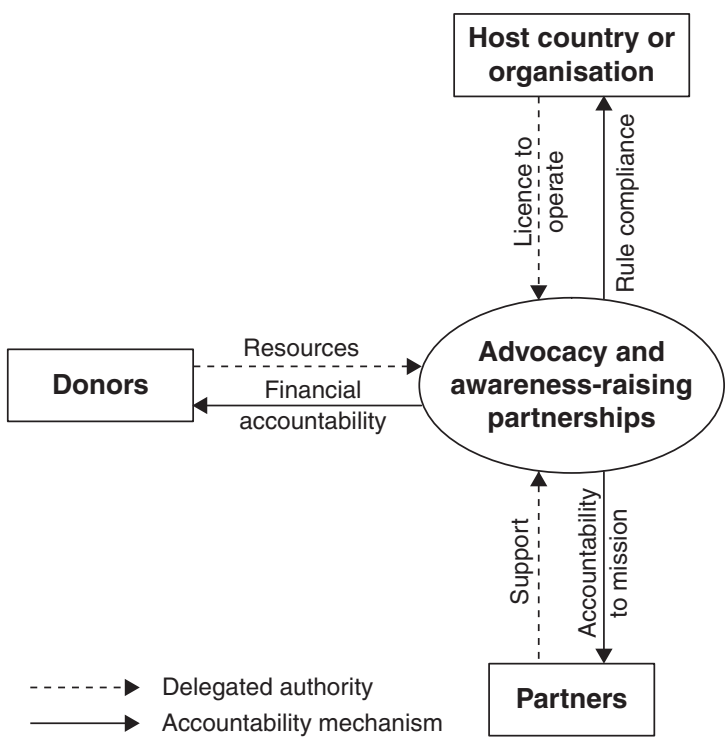

Figure 5.1 Accountability of advocacy and awareness-raising partnerships

Because societies, host institutions and partner organisations grant them the right to operate, partnerships have a duty to ensure they comply with the relevant rules and regulations. These rules are defined by various kinds of institutions and are often linked to different accountability mechanisms.

Firstly, partnerships exercise their activities in specific countries. Wherever they operate, local civil and criminal laws apply. Compliance with civil and criminal legislation is enforced by local court systems. Their efficiency in creating accountability for compliance with laws varies between countries. In well-governed societies with an established tradition of the rule of law, compliance tends to be relatively widespread, even though individual violations can go undetected or remain unpunished. In countries with weak legal systems and rampant corruption, by contrast, illegal behaviour may be common and legal accountability often remains low.

Secondly, many partnerships choose to incorporate or register themselves as independent legal entities. Incorporation and registration usually take place in individual countries and are linked to specific rules and regulations for the chosen form of organisation. It is most common for partnerships to seek registration as tax-exempt organisations or charities. Among the partnerships presented earlier, for example, GRI is incorporated as a Dutch foundation, ICANN is a non-profit, public benefit corporation in California, GAIN is a Swiss foundation, GVEP International is recognised as a charity in the UK, REEEP is an international NGO in Austria, the 4C initiative a Swiss association, the Global Fund a Swiss foundation and MSC an NGO recognised 
as a charity in the UK and with non-profit status in the US. While the exact stipulations vary from country to country, partnerships have to fulfil specific criteria to be recognised as a charity or tax-exempt organisation. This usually includes the requirement to promote an accepted public good, to adopt certain standards relating to the governance of the organisation and to submit regular reports on activities and finances. ${ }^{4}$

The authority to register organisations and to recognise them as charitable or tax-exempt can be vested in different institutions. In some countries, the tax authorities are responsible, in others it is a branch of the judiciary, a government ministry or an independent commission. Irrespective of their institutional identity, these authorities can hold partnerships accountable for complying with the rules linked to registration. Thus if they are not satisfied with the institutional design and purpose of the organisation at the outset, they have the authority to deny registration or recognition. ${ }^{5}$ Moreover, these institutions usually demand regular and standardised reports on the partnership's financial situation and activities. If the partnership fails to comply with this stipulation or if its reports reveal an infraction of other rules, the organisation's charitable status can be revoked. Some charity commissions or registration offices can, in addition, supervise or audit registered organisations in greater detail. If properly applied, these options allow registration offices significant control over partnerships.

Thirdly, partnerships that are not registered as independent legal entities are usually hosted by other organisations. In most cases, one or several of the core partner organisations assume this role. EITI, for example, is hosted by the Norwegian Government, Stop TB and RBM by WHO and GAVI by UNICEF. It also occurs, though it seems to be less common, that external organisations are entrusted with this task. The Voluntary Principles, for instance, have a secretariat hosted jointly by the International Business Leaders Forum and Business for Social Responsibility. The host organisations, especially if they are large and established, have detailed rules governing their operations. Intergovernmental organisations such as UNICEF or WHO are usually free to determine what these rules are. Others, like the International Business Leaders Forum, are themselves registered as charities and must therefore comply with the applicable national rules. However the rules may be defined, a partnership that is hosted by a third organisation thereby becomes subject to its internal rules and regulations.

The mechanisms available for enforcing the internal rules of host organisations vary widely. As ultima ratio, host organisations can terminate their cooperation with the partnership. In addition, more established organisations often have internal disciplinary measures to enforce compliance with their rules. These can include complaints procedures, as well as internal evaluations, audits and disciplinary sanctions. The WHO, for example, has a system of internal controls under the auspices of its director general that includes the review, evaluation and monitoring of all its operations and activities. ${ }^{6}$ 
The institutional set-up of the host organisation is thus an important determinant for the effectiveness of its rules as an accountability mechanism for partnerships. Another important factor is whether the partnership is hosted by one or several institutions. With more than one host organisation, responsibilities are split and more difficult to assign and it is potentially unclear which rules apply in which situation.

Finally, internal rules and processes can support and complement these external and externally enforced rules. Partner organisations usually determine internal rules in the mutual agreement setting up a partnership, in the partnership's statutes or by-laws, in the terms of reference for individual partnership bodies or in a code of conduct for partnership staff. These documents usually define the partnership's mission, goals, targets and values; the composition, function and responsibilities of the various partnership bodies; work processes for taking decisions, accounting, reporting and auditing; as well as rules governing conflicts of interest or other standards for the behaviour of staff members. The by-laws of the Global Fund, for instance, specify the partnership's mission and goals, as well as the purpose, composition, function, responsibilities and working methods for each partnership body. In addition, the partnership has adopted an ethics and conflict of interest policy that, for example, defines standards of conduct for contacts with members of the Global Fund involved in funding decisions. ${ }^{7}$

Partnerships can take various steps to make internal rules effective as accountability mechanisms. Firstly, the rules, processes and responsibilities need to be explicit, clear and known to those concerned. This implies that internal rules and regulations should be available in written form, should cover the most important aspects of the organisation's work and should be communicated adequately to all staff members and partners.

Broadly recognised governance requirements for NGOs also emphasise this point. Thus, for example, the International Center for Not-for-Profit Law identifies as a generally accepted international practice that national laws require non-profits to submit their governance arrangements with registration and may require rules on conflicts of interest. ${ }^{8}$ The Panel on Accountability and Governance in the Voluntary Sector proposes that boards adopt 'a code of ethical conduct and an effective monitoring and complaints procedure' as well as 'a framework for internal regulations, including a constitution and bylaws' (Panel on Accountability and Governance in the Voluntary Sector, 1999, p. 29). Similarly, the International Non Governmental Organisations' Accountability Charter stresses that organisations should have 'written procedures covering the appointment, responsibilities and terms of members of the governing body, and preventing and managing conflicts of interest' (International Non Governmental Organisations, 2006, p. 4). The Handbook on NGO Governance goes into greater detail and suggests that the basic documents of an NGO should include the name of governing body(ies), their relation to other organisational entities, the basic responsibilities and powers 
of different bodies, the duties of individual board members, the minimum number of board members, membership rules, terms of office, number of meetings per year, the method of convening meetings, decision-making procedures and conflict of interest provisions. ${ }^{9}$

Secondly, partnerships need effective oversight to ensure compliance with internal rules. The main responsibility for exercising oversight lies with a formal board or a group of partner organisations exercising board functions. What enables boards or their functional equivalents to fulfil this task effectively? There is a broad literature addressing this question relating to non-profit organisations, which often draws on the more established literature on corporate governance. Researchers reviewing this literature have found it diverse and conclude that 'there is no consensus about an ideal way of governing nonprofit organizations' (Bradshaw et al., 1998, p. 11).

Despite this lack of consensus, most recommendations and codes cover a limited range of recurring themes. ${ }^{10}$ They usually contain measures intended to ensure that board members know their responsibilities and the processes used to exercise oversight. This includes, for example, recommendations that board responsibilities should be clearly defined, standard practices should be described in board manuals and new board members should get an orientation or training. Another group of suggestions aims at creating the preconditions for board members to exercise effective oversight by focusing on their skills and the information available to them. This comprises proposals to select board members with an adequate mix of skills, to ensure they work actively to acquire information about the organisation's activities and that they receive adequate activity and financial reports. A final set of propositions is concerned with the willingness of board members to fulfil their duties. This includes, for example, recommendations to make attendance of board meetings mandatory, to ensure the independence of board members and to create regulations governing conflicts of interest.

Finally, partnership oversight bodies need to be in a position to apply sanctions or incentives to enforce compliance with internal rules. Partnership boards or their functional equivalents can often rely on the following sanctions: Most boards have the authority to accept and control financial and activity reports and to approve future work plans and budgets for the partnership. This means that they can require additional or changed reports and they can veto activities that seem to run counter to internal rules or the partnership's mission. Partnership boards also often hold the authority to appoint and dismiss the partnership's CEO or manager. Thus they can react to suspected misconduct by firing the responsible manager. Finally, core partner organisations, which are often represented on the board, can sanction insufficient compliance with internal rules by withdrawing their support from the partnership. ${ }^{11}$

The first pillar of accountability for partnerships is compliance with relevant rules and regulations. Partnerships have little influence over many 
important factors shaping the effectiveness of external rules and their enforcement systems. They have little bearing, for example, on the quality of national regulatory systems and the reliability of courts in host and operating countries. Likewise, partnerships can rarely influence the quality of governance arrangements of host organisations. But, as the preceding discussion has shown, partnerships can take a range of steps to increase their accountability for complying with relevant external and internal rules and regulations. These measures are the concrete accountability standards that all partnerships, including advocacy and awareness-raising partnerships, should comply with. They include the following elements.

\subsubsection{Choose a well-governed host organisation}

Partnerships usually determine where they want to operate based on their mission and goals, rather than accountability considerations. But they have greater flexibility in choosing their host organisation. For this decision, issues relating to accountability should be strongly considered.

If a partnership incorporates itself as an independent legal entity, for example, it should seek incorporation in a country that has well-defined legal and fiscal rules for private organisations. The host country should also have a well-established and well-functioning legal system and low levels of corruption. Among the case examples, all independently incorporated partnerships heed this advice. They are incorporated in the Netherlands, the US, Switzerland, the UK, Austria or Sweden.

Instead of incorporation, partnerships can also opt for a secretariat or coordinating mechanism hosted by a third organisation. Arrangements like this can create equally strong accountability for complying with relevant rules and regulations if a few principles are respected when choosing the host organisation. Firstly, partnerships should decide on one host organisation, rather than two or more. Where more than one organisation act as hosts, it becomes more difficult to assign responsibilities and determine whose rules apply under which circumstances. Secondly, the organisation chosen as host should itself be incorporated in a well-governed country and/or have a wellestablished and well-functioning internal governance system. Most of the partnerships contained in the case examples are hosted by intergovernmental organisations such as UNEP, WHO or UNICEF.

Partnerships can also be managed by largely informal coordination teams, usually made up of founding partner organisations. The Handwashing with Soap partnership, for instance, is organised by a coordination team from the World Bank and the Water and Sanitation Program, as well as through working groups involving various partner organisations. Arrangements like these diffuse accountability for complying with relevant rules. With various international partners cooperating, it is neither clear which national laws apply to the activities of the partnership, nor can a clear host institution be identified. 
Instead of informal coordination teams, partnerships should therefore either incorporate or choose an organisation to host their secretariat.

\subsubsection{Adopt clear internal rules}

In addition to external rules and regulations defined by host countries or organisations, the founding members of a partnership can define internal rules and processes. Internal regulations are important to ensure that the partnership operates in the way and for the goals intended by the founding partners. Internal rules can also be an additional means for ensuring compliance with external norms.

To establish an effective set of internal rules, partnerships should conform to the following principles:

- Partnerships should state their internal rules, processes and governance arrangements clearly and in writing.

- Internal rules should cover the central elements of the partnership's governance, including all of the partnership's bodies, committees or working groups, detailing their authorities, roles and responsibilities; the processes for taking decisions and reporting on activities and finances; and the ethical standards and values guiding the partnership's work.

- Partnerships should also take measures to ensure that all those concerned, especially members of the oversight body, know the rules and their responsibilities. Basic steps to achieve this include making the rules and procedures easily available and providing new staff and board members with an introduction or training on the rules.

\subsubsection{Create an effective oversight body with the ability to apply sanctions}

In a final important step to create accountability for complying with relevant rules and regulations, partnerships should create an effective internal oversight body. This board or committee monitors whether or not the partnership and its staff comply with relevant rules. Its role is important because it creates awareness about the rules, can have a preventive effect and can uncover and rectify cases of non-compliance or abuse.

Partnerships can take a number of steps to establish an effective internal oversight mechanism:

- Partnerships must clearly assign the responsibility to exercise oversight to one of their bodies or committees, such as the partnership board. When defining these institutional arrangements, partnerships should make sure that the oversight function is clearly separated from management responsibilities. This increases the likelihood that the oversight body will act as an institutional check on partnership management. 
- Partnerships should ensure that members of the oversight body clearly understand their responsibilities. Next to choosing committed individuals to serve on the oversight body, partnerships can support this by highlighting oversight duties during the recruitment process and providing members with written or oral instructions and good practice examples on implementation.

- Partnerships should also make sure that members of the oversight body are in a position to exercise their responsibilities properly. This requires on the one hand that board members have the necessary skills and expertise. Important skills include expert knowledge relating to the thematic focus of the partnership, a good understanding of the legal and regulatory environment for the partnership's work and experience in accounting, reporting and evaluation practices. Individual members do not have to cover all of these areas of expertise, but the oversight body as a whole should. On the other hand, this entails that other partnership bodies supply the oversight body with relevant, timely and accurate information. Oversight bodies should have the formal authority to receive and approve annual financial and activity reports and get regular updates from partnership management. Staff members reporting instances of malpractice can be another important source of information. Policies offering protection to so-called whistleblowers can further encourage a good information flow to the oversight body.

- Effective oversight also depends on the willingness of board members to exercise their responsibilities adequately. Ultimately, their willingness to act lies in the hands of individual board members, but partnerships can take some measures to support them. The first crucial step is to select individuals suited for this task to serve as members of the oversight body. Board members should have high personal integrity and be committed to their role. Members of the oversight body should also be independent, that is, they should not be closely related to management, and the board as a whole should either be neutral or represent the interests of all major stakeholders. Partnerships should also define a policy on conflicts of interest and implement it for their board members.

- Finally, partnerships should give their oversight bodies the authority to apply sanctions. With the means to enforce their conclusions, oversight bodies are both more likely to take their own task seriously and to be taken seriously by other members and bodies of the partnership. The authority and responsibility for accepting annual activity and financial reports is key in this regard. It ensures that the partnership provides members of the oversight body with relevant information and allows the oversight body to demand additional information. This right should be coupled with the authority to sanction management. One possible instrument is the power to accept future work plans and budgets. While this provides 
the oversight body with significant clout, it can also blur the boundaries between management and oversight and undermine the independence of the oversight body. Another, less problematic, possibility is to give the oversight body the authority to hire (potentially subject to a veto of the host organisation) and fire partnership managers.

\subsubsection{Financial accountability}

Institutions or individuals delegate the authority to manage and allocate resources to partnerships. Partnerships, in turn, delegate this authority to their managers and responsible staff members. These instances of delegation give rise to a legitimate demand for financial accountability. Since all partnerships need resources to be able to operate, basic financial accountability is expected of all of them.

In practice, accountability for finances involves various levels. Those who provide the partnership with resources have the most obvious claim for financial accountability. Most partnerships rely predominantly on contributions from partners or external donors. Some, like ICANN also demand fees for the services they provide. Advocacy and awareness-raising partnerships, however, do not usually offer goods or services. The following paragraphs therefore only consider the role of donors - be they partner organisations or external donors - as providers of funds.

Donors have various possibilities for ensuring that their funds are used in the way they intended. Most commonly, the contributions of large donors are linked to specific reporting requirements. They determine when partnerships need to report on their activities and financial decisions. This can range from quarterly or annual to project-related reports. In addition, donors often prescribe the format to be used for reporting. For partnerships depending on various donors all working with different formats, this can create a significant workload and costs.

Donors can also tie their contributions to specific activities or areas. MSC, for example, reports that of the total donations of $£ 2,283,894$ it received in 2006, £740,148 were restricted in their use (Marine Stewardship Council, 2006 , p. 21). Similarly, REEEP received $€ 876,533$ in general donations in the financial year 2005-6, and $€ 5,177,228$ in donations related to specific projects (Renewable Energy and Energy Efficiency Partnership, 2006, p. 39). Tied contributions allow donors to influence relatively directly how their money is spent. At the same time, however, they restrict the flexibility of the recipient organisation and can thus undermine its ability to react to unforeseen circumstances and allocate resources in the most efficient way. ${ }^{12}$

While most of the partnerships surveyed here rely mainly on large institutional donors, some also seek contributions from individuals. Thus, for example, the Stop TB partnership, the Global Fund and MSC all solicit individual donations. Small-scale individual donors cannot negotiate the same conditions to their contributions as large donors. Like them, however, they 
can refuse to donate or discontinue their support. To strengthen the trust of individual donors, these partnerships are therefore likely to create transparency relating to their use of resources. Sometimes, they even allow individual donors to select particular activities they want to invest in.

Another possible donor model that partnerships could rely on is that of a foundation or trust. In this model, donors provide the partnership with a large initial endowment which finances ongoing operations. While none of the case examples analysed here can draw on such an endowment, this would have important implications for the partnership's financial accountability. The main difference to other donor-based financial models is that donors provide all funds upfront. This means that they cannot use the threat to discontinue funding as a sanction. Even more than agreements with large regular donors, the terms connected to an endowment are likely to define very specifically what activities can be supported with the funds and which procedures the partnership needs to comply with when taking decisions.

On a second level, partnerships are held accountable for finances by their host states or other host organisations. Two different rationales can be at work here. In one set of cases, the host organisation also plays the role of a donor. This is the case, for example, when states recognise partnerships as charities or tax-exempt institutions. As discussed above, this status usually restricts the range of permissible activities and is linked to special reporting requirements.

In another set of cases, host organisations do not act as donors. Instead, they use their authority to grant partnerships the 'licence to operate' and include rules on financial accounting and reporting as part of their overall rules and regulations. The Global Partnership to Stop TB, for example, is hosted by WHO. As part of its role as a host, WHO is responsible for financial administration. While the coordinating board takes decisions with financial implications, WHO can veto those on administrative grounds.

On a third level, partnerships further delegate the authority over resources internally. Thus, in a typical set-up such as the one chosen by GAIN, donors provide the partnership with resources. Internally, the partnership board bears fiduciary responsibility. It approves the partnership's annual work plan and budget, receives and approves activity and financial reports and appoints the executive director of the secretariat. The executive director appoints further staff members and delegates operational authority to allocate and account for financial resources to them. Internal rules and procedures on the handling, accounting and reporting of finances, linked to internal oversight mechanisms, can help to ensure that financial accountability is created at this level as well.

Financial accountability, then, is created at various levels. As with accountability for complying with relevant rules and regulations, partnerships cannot freely determine all relevant parameters at all of these levels. In order to ensure an adequate level of financial accountability, advocacy 
and awareness-raising partnerships, as well as partnerships fulfilling other functions, should adopt the following basic accountability standards relating to finances.

\subsubsection{Adopt a system of internal financial controls}

Internal controls are the first step towards establishing financial accountability. They include policies and processes designed to manage the risk of fraud and misappropriation. They serve to ensure that resources are used as intended and that they are accounted for properly.

A standard set of basic internal control measures are generally accepted as good practice for any kind of organisation handling resources. For NGOs, these basic standards have been articulated, for example, by the Charity Commission for England and Wales, by Mango, a non-profit organisation working to improve the financial management of NGOs, and by the Office of New York's Attorney General. ${ }^{13}$ The recommendations issued by these as well as other institutions contain broadly similar components and are subject to little controversy.

Advocacy and awareness-raising partnerships, as well as other types of partnerships, should adopt the key elements of these standards. They include the following measures:

- Partnerships should have a clear internal delegation of responsibilities relating to resources. Ideally in a written format, the authorities to receive payments, authorise expenditures, maintain accounts, oversee accounting processes and prepare and approve budgets should be clearly assigned to individual staff or board members. It is also important to ensure that the assigned individuals have the necessary skills and qualifications to exercise their respective responsibilities.

- When assigning the various responsibilities, partnerships should ensure that key duties are separated and a system of checks and balances is established. Thus, for example, a single individual should not be responsible at the same time for processing complete transactions and recording them. Similarly, accounts should not be controlled by the person responsible for recording transactions in the first place. Moreover, significant expenditures should require the approval and signatures of more than one individual.

- To enable oversight and control over their activities, partnerships should operate on the basis of budgets and financial plans. Regular reconciliations between the planned budget and actual incomes and expenditures as well as reconciliations between partnership records and actual cash, property and bank deposits should be carried out.

- Finally, partnerships should adopt controls for cash and other assets. Cash and valuables should, for example, be kept in a safe place to which general access is restricted. Partnerships should keep a register of assets with 
individual reference numbers for objects. Receipts should be issued for money received and expenditures should be supported by documentation. In addition, partnerships should reduce cash transactions to a minimum and adopt policies to safeguard investments and fixed assets.

\subsubsection{Adopt accounting and reporting policies complying with donor demands and generating reliable, relevant, comparable and understandable information}

Adequate accounting and reporting policies are a further element of a system of internal financial controls. They are the cornerstones of financial accountability to internal as well as external principals.

A partnership's accounting system tracks incomes, expenditures and changes in assets. It enables those responsible to uncover instances of fraud and misappropriation. Reports are based on the data generated by the accounting system. They collect and present relevant information in a systematic manner. They usually cover not only the organisation's finances but also its activities and achievements. Reports thus serve to assess the financial situation of a partnership. They allow analysing whether spending decisions and activities conform to the partnership's policies and relevant external rules. Importantly, they also help establish what the partnership has achieved and how efficiently it works.

Which criteria, though, do accounting and reporting policies need to comply with to create a true and fair view of an organisation? There is a general consensus that the generated information must be relevant, reliable, comparable and understandable. These criteria were defined by the International Accounting Standards Board (IASB). ${ }^{14}$ The IASB is an independent, private organisation based in London, leading efforts to create internationally recognised accounting and reporting standards. It issues the International Financial Reporting Standards (IFRS). These standards are not automatically binding but are adopted by an increasing number of countries. Thus, for example, the European Union endorses many IFRSs and incorporates them into European law.

The standards defined by IASB mainly apply to corporations and there is no equivalent body setting standards for NGOs that could be applied to advocacy and awareness-raising partnerships. ${ }^{15}$ In the absence of international standards specifically designed for NGOs, many see the UK Charity Commission's Statement of Recommended Practice (SORP) on Accounting and Reporting for Charities as an important reference document. The statement reflects the same general principles of relevance, reliability, comparability and understandability (Charity Commission for England and Wales, 2005, p. 10).

These general principles are relatively abstract. How can they be translated into practice? Answering this question requires consideration for a broad array of specific and often complex issues. Without going into too much detail, the following paragraphs discuss which specific standards are emerging 
for the accounting practices of non-profit organisations. They then discuss requirements for reports to internal governing bodies, donors and public authorities.

Relevant and broadly accepted criteria for the accounting practices of nonprofit organisations, which can be applied to advocacy and awareness-raising partnerships, have been defined in several documents. Firstly, as already mentioned, the UK Charity Commission's SORP on Accounting and Reporting for Charities is a widely used reference document. It often refers to principles laid down by the UK Financial Reporting Council and its Accounting Standards Board. This body defines Statements of Standard Accounting Practice (SSAPs) and Financial Reporting Standards (FRSs), most of which also apply to NGOs or charities. ${ }^{16}$ Secondly, due to the large number of non-profit organisations registered in or financed by the US, the Generally Accepted Accounting Practices (GAAP) in force there also enjoys wide recognition. The main institution defining GAAP for charities in the US is the Financial Accounting Standards Board (FASB). Its statements 93, 116, 117, 124 and 136 set down important accounting practices. ${ }^{17}$

These documents contain an emerging consensus on accounting rules that are specific to non-profit organisations and go beyond or deviate from generic good accounting practices:

- Non-profit organisations should distinguish their incomes and assets depending on whether or not their use has been restricted by donors. They should also include certain in-kind contributions of services as incomes. ${ }^{18}$

- Non-profits should account separately for expenses related to their mission or function and those amounting to overhead costs. ${ }^{19}$

- Non-profit organisations should also, like companies, report the gains and losses made on assets and investments. In doing so, they should report assets and investments at their fair value and take account of depreciation. ${ }^{20}$

Detailed and broadly accepted accounting standards, then, have been defined for charitable organisations and NGOs. Since advocacy and awareness-raising partnerships are functionally similar to non-profit organisations, they should comply with these accounting standards.

Based on the information generated through the accounting system, partnerships should also prepare regular financial and activity reports. The authority over financial resources allowing a partnership to cover its operational costs is often delegated by various parties. Partnerships should therefore issue reports at different levels, including reports to internal supervisory bodies, reports to donors and reports to host organisations or fiscal authorities. To date, only few broadly accepted standards for those reports have emerged. The issue is further complicated by the fact that requirements differ depending on the addressees and the purposes pursued by individual reports. 
Firstly, partnerships should prepare internal reports for their governing bodies, such as partnership boards or meetings of core partners. As already discussed, it is broadly accepted as a standard of good governance for nonprofit organisations that boards or their functional equivalents bear fiduciary responsibility. Boards usually take strategic decisions but delegate the task of managing and allocating resources to the organisations' management and staff. They exercise control by approving work-plans and budgets and by receiving regular reports. There are no commonly accepted standards defining criteria for these internal reports. Beyond the basic requisite that reports should be accurate and understandable, however, the purpose of board reports dictates some necessary conditions:

- Internal reports should be frequent and be made available regularly before the supervisory body convenes.

- Partnership boards or equivalent bodies exercise control through their approval of work-plans and budgets. Internal reports should therefore provide the necessary information to allow for an accurate comparison between those documents and the partnership's actual activities, incomes and expenditures.

- Internal reports should also support the supervisory body in its strategic planning role. To this aim, they should include information on projected future financial developments, the financial implications of key decisions and the relative effectiveness and efficiency of individual programmes and activities.

Secondly, partnerships should submit regular reports to their donors. The partnerships described in the case examples rely mainly on the financial and other contributions of donors to cover their operational expenses. The reports should enable donors to assess whether the partnership has fulfilled potential conditions attached to the contributions. Moreover, they should allow donors to establish whether or not the resources were used, and were used efficiently, to achieve the intended purposes. Which format these reports take and whether commonly accepted standards for their content exist depends on the type of donor involved.

States represent one important kind of donor. Governments can sponsor partnerships as well as other organisations directly. In terms of creating standard reporting requirements, however, their role as indirect donors or supporters is more important. As discussed earlier, many partnerships are incorporated as independent legal entities and enjoy the status of tax-exempt charities or non-profit organisations. As such, they face special reporting requirements defined by state authorities. Because of their widespread application, these requirements often turn into more generally used parameters for external reporting. This is especially the case where other donors demand 
similar information or where the official reports are openly accessible and are used as a basis for assessing non-profit organisations.

Due to the large number of charities registered there, the annual reports requested by the Internal Revenue Service (IRS) of the US Department of the Treasury are seen as an important model for official reports. ${ }^{21}$ In the US, all registered charities with annual revenues exceeding US\$25,000 must file a completed IRS form 990 every year. ${ }^{22}$ On this form, non-profits have to report their revenues, expenses (differentiating between programme expenses, administrative costs, fund-raising expenses and payments to affiliates) and changes in their net assets. Moreover, they have to provide balance sheets, details on functional expenses, lists of key current and former staff members, directors and trustees and discuss their activities and achievements. Following a regulation of 1999 , non-profits have to make the three most recent IRS filings available to anyone interested upon request. ${ }^{23}$ With IRS data publicly available, it has become an important source of information for NGO assessments. GuideStar, for example, is an organisation collecting information on non-profit organisations and rating their accountability. It relies heavily on data derived from IRS form $990 .{ }^{24}$

The reporting requirements in other important host states for non-profit organisations including partnerships tend to be broadly similar. In the UK, charities with an annual income exceeding $£ 10,000$ must file an annual return with the Charity Commission. ${ }^{25}$ What information charities need to include depends on their size. With revenues below $£ 250,000$, they need to list their total incomes and expenditures, the contact details of trustees and a summary of their activities. Above $£ 250,000$, charities need to include further details on fund-raising, benefits for trustees, properties, relations to connected trading companies and instances of misappropriation. If revenues exceed $£ 1$ million, charities have to include a 'summary information return', which differentiates income by sources and contains additional information on aims, strategy, activities and achievements, as well as programme expenditures, governance and future plans. Through the Charity Commission's website, all filed reports are publicly accessible and they are used by agencies like GuideStar UK to evaluate organisations. ${ }^{26}$

For partnerships incorporated as tax-exempt institutions or charities, then, official annual returns are an important element of financial accountability. Filing these reports is not optional. To fulfil their reporting duty adequately, partnerships should:

- Incorporate important reporting parameters into their accounting system from the outset. If the official annual return requires, for example, to distinguish between different types of incomes and expenditures, only an accounting system that mirrors these criteria can deliver the necessary information. 
- Complete all required sections of the report and verify the accuracy of the data.

- Prepare and file reports in a timely manner.

- Make copies of the report available to interested parties, preferably by posting it on the Internet.

Institutional and individual contributors are another important kind of donor. Among the partnerships surveyed for this book, most rely on governments, multilateral institutions, corporations and foundations as their main donors.

Large donors tend to attach conditions, including specific reporting requirements, to their contributions. Problems can arise when partnerships depend on a range of large donors, each imposing different reporting conditions. To reduce the resulting administrative burden, partnerships can try to negotiate with donors to achieve a harmonisation of reporting requirements. This could, for example, involve a convergence of standards around the criteria for official annual returns. ${ }^{27}$

Some partnerships, such as Stop TB for example, also solicit individual contributions. In this case, partnerships need to be more proactive for providing adequate reports to donors. Small individual donors may not be powerful enough to set their own reporting rules, but they do have a right to receive adequate information on how their funds are spent. In addition, they can sanction organisations violating this right by refusing future support. Partnerships should therefore publish regular reports for small donors of their own accord.

The most relevant and broadly accepted existing standards for public annual reports of advocacy and awareness-raising partnerships are again those contained in the UK Charity Commission's SORP on Accounting and Reporting by Charities. ${ }^{28}$ According to this document, an annual report should contain reference and administrative details for the charity, its trustees and advisors; information on the organisation's structure, governance and management; a statement of its objectives and activities; an analysis of its achievements and performance; a financial review; as well as an explanation of future plans (Charity Commission for England and Wales, 2005, pp. 7-9). For the summarised financial statements, the commission specifies that they should contain information on both financial activities and the balance sheet, that they ought to be consistent with statutory accounts and that they should not be misleading either through omission or inappropriate amalgamation.

Regarding their reports to direct donors, advocacy and awareness-raising partnerships should therefore comply with the following principles:

- Comply with the reporting requirements set by large donors or negotiate those terms. 
- Partnerships relying on or intending to reach small individual donors should in addition publish an annual report containing accurate and not misleading summary financial information and describing the organisation's activities and achievements.

Thirdly and finally, partnerships must report to their host organisations. In this case, the demand for financial accountability is not based on financial support. Rather, it is part of the general rules and regulations that host organisations can attach to the licence to operate. Partnerships can, for example, be incorporated as independent legal entities without receiving indirect state support through tax exemption. The local fiscal authorities will nevertheless demand detailed annual financial reports to determine the organisation's tax burden and to verify its compliance with other rules. Similarly, partnerships hosted by a third organisation usually have to report regularly on their activities and finances. Again, the reports serve to establish whether the partnership complies with internal rules and regulations. Moreover, the reports deliver necessary information to host organisations enabling them to fulfil their reporting duties.

To strengthen their financial accountability through adequate reporting to host organisations, partnerships should ensure they follow relevant rules and regulations as described in section 5.1.1.

\subsubsection{Conduct independent audits for large partnerships}

Financial audits work to control an organisation's accounting and reporting practices. ${ }^{29}$ They involve internal or external professionals assessing the fairness of financial statements and their compliance with GAAP or the IFRS. Auditors do not usually verify an organisation's accounts in all their detail. Instead, they most often use a sampling technique to test accounting practices.

Independent, external financial audits provide the strongest assurance that financial statements are fair. External auditors have to fulfil strict professional qualification criteria. ${ }^{30}$ Commissioning an external audit can therefore incur significant costs. ${ }^{31}$ Regulations determining audit requirements often differ depending on the kind of organisation concerned. Thus it is common that publicly traded companies are generally required to have independent audits. Private companies below a certain financial turnover threshold are usually exempt from audit requirements. ${ }^{32}$ For NGOs and non-profit organisations, audit regulations vary strongly even among leading Western countries. Over recent years, however, a trend has been emerging to make audits obligatory for large NGOs exceeding specified financial thresholds. ${ }^{33}$

In the UK, for example, charities whose gross income exceeds $£ 500,000$ or charities with a gross income over $£ 100,000$ and assets exceeding $£ 2.8$ million must commission an independent audit. ${ }^{34}$ In the US, organisations receiving federal or state grants of US\$500,000 or more must have an independent 
audit. ${ }^{35}$ So far, non-profits that do not rely on major government grants are not subject to an audit requirement. An important recent panel, though, was encouraged by leaders of the US Senate Finance Committee to propose reforms to strengthen the governance and accountability of the non-profit sector. In its final report, the panel recommends the introduction of external audits for non-profit organisations with total annual revenues exceeding US\$1 million. ${ }^{36}$

The practice of demanding obligatory audits has not been consistently implemented in other countries. Despite this, evaluation agencies focusing on NGOs have adopted the standard. The Standards for Charitable Accountability of the BBB Wise Giving Alliance, for example, states that organisations with an annual gross income of over US\$250,000 should have an external audit (BBB Wise Giving Alliance, 2003, §11). Moreover, many larger NGOs recognise their obligation to provide audited financial statements. In their Accountability Charter, for example, a range of international NGOs commit to attaching audit results to the financial data they present in annual reports (International Non Governmental Organisations, 2006, p. 4). ${ }^{37}$

Since there is an emerging consensus that non-profit organisations with substantial revenues should undergo independent audits, the same standard should apply to advocacy and awareness raising as well as other partnerships. Defining a financial threshold after which the standard applies is necessarily somewhat arbitrary. For NGOs, the revenue threshold is often between $€ 500,000$ and 1 million. For private companies, though, audit exceptions can apply up to a turnover of $€ 8.8$ million. The threshold chosen here presents a relatively conservative limit because the consensus on audit requirements is still emerging and not yet firmly established. Therefore, and due to the high costs of audits, only partnerships with annual budgets exceeding $€ 5$ million should be subject to independent, external audits to strengthen financial accountability.

To be effective, audits have to fulfil certain principles. The most basic requirement is that only professional and independent auditors should conduct audits. As for accounting, other, more detailed auditing standards have been defined by various professional and regulatory bodies. At the international level, a crucial rule-setting institution is the International Federation of Accountants (IFAC) and its International Auditing and Assurance Standards Board (IAASB). It sets the International Standards on Auditing (ISAs). ISA 200, for example, defines the 'objective and general principles governing an audit of financial statements' and applies to audits in all sectors. ${ }^{38}$ It requires auditors to comply with the IFAC Code of Ethics for Professional Accountants (International Federation of Accountants' Ethics Committee, 2005), to adopt an attitude of professional scepticism, to reduce audit risk, to obtain reasonable assurance that financial statements are free from material misstatements and to determine whether the financial reporting framework adopted by the organisation under scrutiny is acceptable (International Federation 
of Accountants, 2007, pp. 213-29). ${ }^{39}$ Audits on the financial statements of partnerships should comply with relevant international and national auditing standards.

In summary, partnerships should observe the following principles relating to audits:

- Partnerships with annual budgets exceeding €5 million should submit their financial statements to professional, independent audits.

- The audits should comply with applicable ISAs, as well as relevant additional national regulations.

- Audit results should be published together with the audited financial statements.

\subsubsection{Accountability for working towards the partnership's mission}

Finally, advocacy and awareness-raising partnerships need the general support of partners or members to be able to work effectively. 'General support' is a more diffuse notion than either the granting of a licence to operate or the delegation of authority over operational resources. It is therefore also less immediately clear which kind of accountability demand follows from the granting of support.

The lack of clarity stems from two factors. Firstly, general support can manifest itself in different ways depending on the orientation of the partnership. Partnerships like PCFV focus mainly on advocacy campaigns to influence important decision makers. Support in this case means that partners subscribe to this call and grant the partnership the authority to speak on their behalf when advancing its claims. Partnerships like REEEP aim to serve as information hubs. Here, active support implies that partners supply their information to the partnership and use and integrate the information offered by the partnership in their work. Advocacy and awareness-raising partnerships can also emphasise their role as coordinators, as does, for example, RBM. In that case, support entails that partners accept the authority of RBM to propose modalities for coordination.

Secondly, partner organisations can have very different motives for joining or supporting partnerships. Businesses, for example, are often interested in showing good corporate citizenship, increasing their reputation or improving their investment markets. Governments and intergovernmental organisations may be driven by a desire to mobilise additional resources, by the urge to demonstrate leadership or by the wish to develop more effective approaches to problem solving. NGOs, in turn, can in addition be motivated by the desire to gain influence over key decisions. ${ }^{40}$ These different motives give rise to different expectations of what partnerships should deliver. Partner organisations will therefore hold a partnership to account by either continuing or withdrawing their support depending on different performance criteria. 
Despite these variations, support is in all cases closely linked to partnership mission. As described above, the partnership's mission strongly influences what support entails in practice. Moreover, the partnership's mission usually serves as a common denominator for all partner organisations. These organisations are presumably only willing to join a particular partnership with its specific mission if they believe that this meets their expectations. Both, a company trying to enhance its reputation and a government seeking new ways to address public policy problems, for example, can only achieve their objectives if the partnership works successfully towards its own goals.

In exchange for the general support of their partners and members, advocacy and awareness-raising partnerships should therefore be accountable for working towards achieving their mission. To create this kind of accountability, partnerships should follow some basic standards in their work:

\subsubsection{Define a clear mission}

An obvious and necessary precondition for making partnerships accountable to their mission is to have a clearly defined and understood mission. Writing down a clear and meaningful mission statement is not always an easy task. The challenge is to define a goal and vision that is broad and flexible enough to integrate various actors with potentially very different interests and to allow the partnership to adapt flexibly to changing circumstances. At the same time, however, the mission statement should be specific enough to have meaning for partners and supporters and to be able to guide strategic planning and programming.

The Stop TB partnership provides a good example for the required level of specificity of mission statements. The partnership pursues the strategic goal of eliminating tuberculosis as a public health problem and achieving a world free of TB. In this quest, it defines its mission as follows:

To ensure that every TB patient has access to effective diagnosis, treatment and cure; To stop the transmission of TB; To reduce the inequitable social and economic toll of TB; To develop and implement new preventive, diagnostic and therapeutic tools and strategies to stop TB.

(http://www.stoptb.org/stop_tb_initiative/\#vmg, last accessed 27 August 2009)

To ensure their mission is clear, meaningful and relevant, partnerships should adhere to the following principles: ${ }^{41}$

- Partnerships should adopt mission statements that are specific enough to provide guidance for their strategic planning and the development of programmes and activities. 
- Mission statements should be published in a prominent position in publications and reference documents and should be known to the partnerships' key stakeholders.

- To increase the mission statement's practical relevance and ensure that it is and continues to be backed by partner organisations, partnerships should periodically discuss and review their missions.

\subsubsection{Orient partnership activities along the mission}

Once a partnership has created a clear and meaningful mission statement, the next challenge is to ensure its relevance to the partnership's activities. Accountability to mission implies that the mission statement plays a central role in the planning and work of a partnership. This can be achieved if the following principles are respected:

- Partnerships should not conduct any major activities that are unrelated to their mission. Instead, all important elements of their work programmes should promote their mission.

- Mission statements should guide the strategic planning of partnerships. Using a results chain or logical framework approach, ${ }^{42}$ partnerships should identify which courses of action are likely to contribute to achieving their mission and select them accordingly.

- To make the rationale behind their work programmes transparent, partnerships should also structure their activity reports around their mission. These reports should contain an explanation of how the partnership's main efforts are intended to contribute to the mission. Moreover, activity reports should portray the partnership's achievements, the obstacles it encountered and the consequences it drew from past experiences.

\subsubsection{Employ resources efficiently in pursuit of the mission}

Finally, an organisation intent on creating accountability for working towards its mission needs to demonstrate that it uses its resources efficiently in pursuing its goals. Measuring efficiency in organisations addressing public policy problems is notoriously difficult, because they have no clearly defined bottom line and address complex issues. ${ }^{43}$

Most efforts to evaluate the efficiency of public policy programmes rely on benchmarks. Benchmarking is a technique originally developed by companies. It involves identifying the best competitor and using that organisation's performance as a yardstick. ${ }^{44}$ Benchmarking can be a useful tool for assessing the relative efficiency of partnerships or other organisations working in the same field. It could be used, for example, to compare the efficiency of the Global Fund, RBM and other health providers in fighting malaria. Benchmarking, however, cannot usually serve to establish detailed 
efficiency criteria that would be applicable to organisations working in different fields.

The efficiency standards defined here for advocacy and awareness-raising partnerships therefore have to remain very general. They include the following basic principles and criteria:

- Partnerships should define priorities for the allocation of scarce resources depending on how efficiently the various possible activities contribute to the achievement of the partnership's mission. ${ }^{45}$ To create a reliable basis for these decisions, partnership boards or management should encourage evaluations of ongoing programmes.

- Partnerships should control their costs related to administration and fund-raising and ensure that the clear majority of their resources is spent on programme activities. Following a broadly accepted benchmark for NGOs, partnerships should at the very least allocate 65 per cent of their total funds to activities designed to directly contribute to mission achievement. ${ }^{46}$

\subsubsection{Summary of standards}

Table 5.1 contains a summary of relevant accountability standards for advocacy and awareness-raising partnerships.

Table 5.1 Accountability standards for advocacy and awareness-raising partnerships

\begin{tabular}{lll}
\hline $\begin{array}{l}\text { Accountability } \\
\text { principles }\end{array}$ & $\begin{array}{l}\text { Accountability } \\
\text { standards }\end{array}$ & Practical steps \\
\hline $\begin{array}{l}\text { Compliance with } \\
\text { rules and regulations }\end{array}$ & $\begin{array}{l}\text { Choose a well- } \\
\text { governed host } \\
\text { organisation }\end{array}$ & $\begin{array}{l}\text { Incorporate as an independent legal } \\
\text { entity in a country with well-defined } \\
\text { rules for private organisations and a } \\
\text { well-established and functioning legal } \\
\text { system } \\
\text { Or choose one organisation to host } \\
\text { the partnership, which is itself well } \\
\text { governed } \\
\text { Adopt clear internal } \\
\text { rules }\end{array}$ \\
& $\begin{array}{l}\text { Clearly define internal rules, processes } \\
\text { and governance arrangements }\end{array}$ \\
& $\begin{array}{l}\text { Rules cover roles and responsibilities } \\
\text { of partnership bodies, decision-making } \\
\text { procedures, reporting requirements } \\
\text { and ethical standards }\end{array}$ \\
& $\begin{array}{l}\text { Ensure that internal rules are known } \\
\text { to all those concerned, especially the } \\
\text { oversight body }\end{array}$ \\
&
\end{tabular}


Table 5.1 Continued

\begin{tabular}{|c|c|c|}
\hline $\begin{array}{l}\text { Accountability } \\
\text { principles }\end{array}$ & $\begin{array}{l}\text { Accountability } \\
\text { standards }\end{array}$ & Practical steps \\
\hline & $\begin{array}{l}\text { Create an effective } \\
\text { oversight body with } \\
\text { the ability to apply } \\
\text { sanctions }\end{array}$ & $\begin{array}{l}\text { Clearly assign responsibility for } \\
\text { oversight to one body or committee } \\
\text { and separate it from management } \\
\text { responsibility }\end{array}$ \\
\hline & & $\begin{array}{l}\text { Ensure members of the oversight } \\
\text { body understand their responsibilities } \\
\text { by choosing committed individuals, } \\
\text { emphasising responsibilities during } \\
\text { recruitment and offering } \\
\text { information }\end{array}$ \\
\hline & & $\begin{array}{l}\text { Ensure that members of the oversight } \\
\text { body have the necessary skills and } \\
\text { expertise and are adequately supplied } \\
\text { with information, including through } \\
\text { whistle-blower protection }\end{array}$ \\
\hline & & $\begin{array}{l}\text { Select independent individuals with } \\
\text { strong personal integrity to serve on } \\
\text { the oversight body and adopt a conflict } \\
\text { of interest policy }\end{array}$ \\
\hline & & $\begin{array}{l}\text { Enable members of the oversight body } \\
\text { to apply sanctions and incentives }\end{array}$ \\
\hline \multirow[t]{7}{*}{$\begin{array}{l}\text { Financial } \\
\text { accountability }\end{array}$} & \multirow{4}{*}{$\begin{array}{l}\text { Adopt a system of } \\
\text { internal financial } \\
\text { controls }\end{array}$} & $\begin{array}{l}\text { Clearly delegate internal } \\
\text { responsibilities for resources }\end{array}$ \\
\hline & & $\begin{array}{l}\text { Separate key duties and install a system } \\
\text { of checks and balances }\end{array}$ \\
\hline & & $\begin{array}{l}\text { Operate on the basis of budgets and } \\
\text { financial plans }\end{array}$ \\
\hline & & $\begin{array}{l}\text { Adopt controls for cash and other } \\
\text { assets }\end{array}$ \\
\hline & \multirow{3}{*}{$\begin{array}{l}\text { Adopt accounting } \\
\text { policies generating } \\
\text { reliable, relevant, } \\
\text { comparable and } \\
\text { understandable } \\
\text { information }\end{array}$} & $\begin{array}{l}\text { Distinguish incomes and assets } \\
\text { depending on whether or not their use } \\
\text { has been restricted by donors }\end{array}$ \\
\hline & & $\begin{array}{l}\text { Account separately for expenses } \\
\text { related to mission/function and } \\
\text { overhead costs }\end{array}$ \\
\hline & & $\begin{array}{l}\text { Report gains and losses made on } \\
\text { assets and investments, using their } \\
\text { fair value and accounting for } \\
\text { depreciation }\end{array}$ \\
\hline
\end{tabular}


Table 5.1 Continued

\begin{tabular}{|c|c|c|}
\hline $\begin{array}{l}\text { Accountability } \\
\text { principles }\end{array}$ & $\begin{array}{l}\text { Accountability } \\
\text { standards }\end{array}$ & Practical steps \\
\hline & $\begin{array}{l}\text { Adopt reporting } \\
\text { practices generating } \\
\text { reliable, relevant, } \\
\text { comparable and } \\
\text { understandable }\end{array}$ & $\begin{array}{l}\text { Internal reports should be available } \\
\text { before board meetings, enable a } \\
\text { comparison between budgets, } \\
\text { work-plans and actual activities and } \\
\text { enable strategic planning }\end{array}$ \\
\hline & $\begin{array}{l}\text { information and } \\
\text { complying with } \\
\text { donor demands }\end{array}$ & $\begin{array}{l}\text { Incorporate reporting requirements in } \\
\text { the accounting system, file complete } \\
\text { and accurate returns on time and make } \\
\text { them publicly available on request }\end{array}$ \\
\hline & & $\begin{array}{l}\text { Reports to donors should comply } \\
\text { with the conditions set by large } \\
\text { donors; partnerships relying on small, } \\
\text { individual donors should publish } \\
\text { annual reports including a financial } \\
\text { review and information on activities } \\
\text { and achievements }\end{array}$ \\
\hline & $\begin{array}{l}\text { Conduct } \\
\text { independent } \\
\text { audits for large }\end{array}$ & $\begin{array}{l}\text { Partnerships with annual budgets } \\
\text { exceeding } € 5 \text { million should undergo } \\
\text { professional, independent audits }\end{array}$ \\
\hline & partnerships & $\begin{array}{l}\text { Audits should comply with relevant } \\
\text { ISAs and national regulations }\end{array}$ \\
\hline & & $\begin{array}{l}\text { Audit results should be published } \\
\text { alongside financial statements }\end{array}$ \\
\hline \multirow{8}{*}{$\begin{array}{l}\text { Accountability for } \\
\text { working towards } \\
\text { the partnership's } \\
\text { mission }\end{array}$} & $\begin{array}{l}\text { Define a clear } \\
\text { mission }\end{array}$ & $\begin{array}{l}\text { Mission statements should be specific } \\
\text { enough to guide strategic planning and } \\
\text { programming }\end{array}$ \\
\hline & & $\begin{array}{l}\text { Publish mission statements } \\
\text { prominently and ensure it is } \\
\text { understood by stakeholders }\end{array}$ \\
\hline & & $\begin{array}{l}\text { Periodically discuss and review mission } \\
\text { statements }\end{array}$ \\
\hline & $\begin{array}{l}\text { Orient activities } \\
\text { along the mission }\end{array}$ & $\begin{array}{l}\text { Do not conduct any major activities } \\
\text { unrelated to partnership mission }\end{array}$ \\
\hline & & $\begin{array}{l}\text { Use mission statements as a guide to } \\
\text { strategic planning }\end{array}$ \\
\hline & & $\begin{array}{l}\text { Structure activity reports around the } \\
\text { mission }\end{array}$ \\
\hline & $\begin{array}{l}\text { Employ resources } \\
\text { efficiently in pursuit } \\
\text { of the mission }\end{array}$ & $\begin{array}{l}\text { Define priorities based on mission- } \\
\text { related efficiency and evaluate } \\
\text { ongoing programmes }\end{array}$ \\
\hline & & $\begin{array}{l}\text { Control overhead costs and ensure } \\
\text { they do not exceed } 35 \text { per cent of total } \\
\text { revenues }\end{array}$ \\
\hline
\end{tabular}




\subsection{Standards for rule setting and regulation partnerships}

A second group of partnerships comprises those engaged in defining new rules, standards or regulations for specific policy areas or groups of organisations. GRI, for example, develops standards and guidelines for sustainability reporting, ICANN regulates important aspects of the Internet, WCD has created criteria for decisions relating to the building of large dams, MSC developed rules for sustainable fisheries, EITI has proposed standards on transparency in the extractive industries and the Voluntary Principles created guidelines for the security arrangements of companies.

In all those cases, compliance with the proposed rules or regulations is ultimately voluntary. The partnerships chosen as case examples here all operate at the international level. Thus they work outside the realm of nation states and their rule-making and rule-enforcement systems. The proposed norms do also not enjoy the status of international law. To be considered as binding under international law, governments either have to back norms through explicit agreement or through consistent customary practice. ${ }^{47}$ The partnerships analysed here, however, usually only include a very limited number of governments, their rules have not (yet) become common state practice and do often not address states but companies or other organisations. ${ }^{48}$

Yet the rules and regulations defined by partnerships are not always and not necessarily non-binding. Partnerships can, for example, involve private actors in the decision-making processes of official norm-setting institutions, such as national parliaments or international conventions. The results of the work of these partnerships are immediately incorporated into national or international law and are therefore binding. In addition, even voluntary rules set by partnerships can assume a de facto binding character when the affected stakeholders depend strongly on the partnership.

The rules and regulations defined by partnerships are thus very often, but not necessarily, non-binding. What does this imply for the authority delegated to or assumed by rule-setting partnerships? As discussed in detail in section 3.2.3, especially organisations operating at the inter- or transnational level often lack prior authorisation. Instead, they rely on ex-post or even hypothetical delegation to legitimise their activities. Most of the rule-setting partnerships under scrutiny here operate in the hope that as many relevant actors as possible will comply voluntarily with the proposed rules and thus accept them as binding for themselves. In order to achieve this kind of ex-post authorisation, rule-setting partnerships should therefore adopt the same accountability arrangements as if they had the authority to determine binding rules.

What, then, are the accountability principles linked to the authority to set binding rules? Building on respect for the principle of autonomy, the authority to determine rules requires democratic accountability. Rule-setting partnerships should therefore focus on creating democratic accountability to 


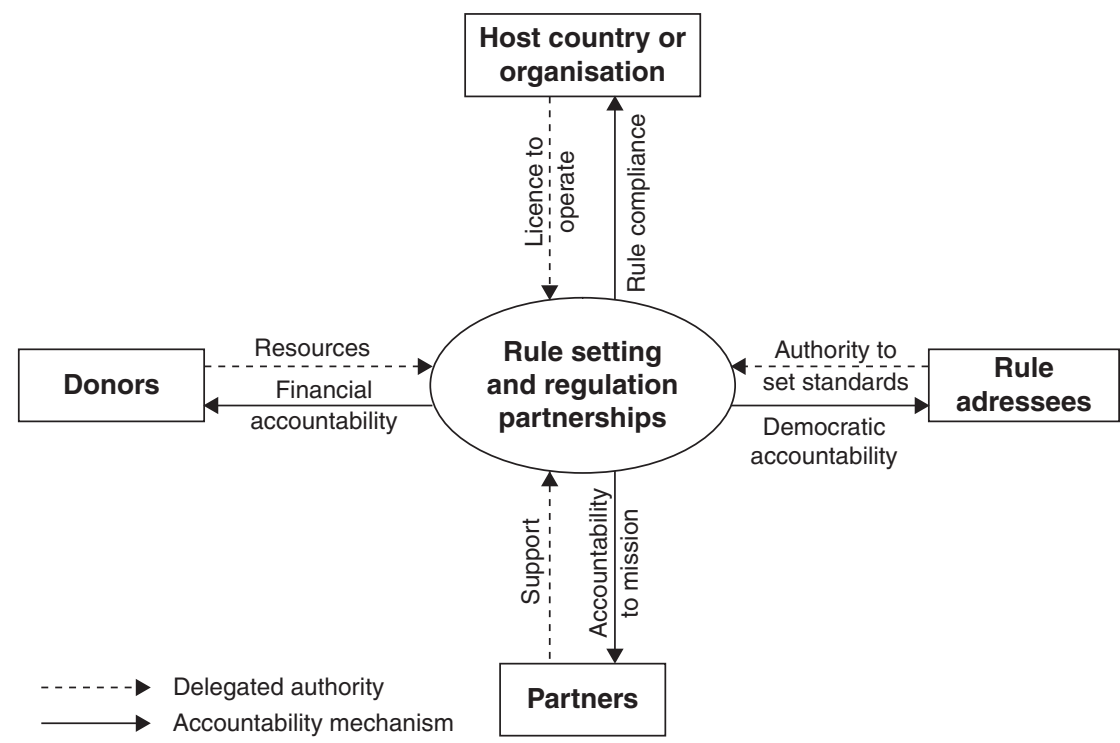

Figure 5.2 Accountability of rule setting and regulation partnerships

those delegating the authority to establish rules. This accountability focus, in addition to the basic accountability standards defined in the previous section, is depicted in Figure 5.2.

\subsubsection{Applying democratic accountability standards to rule-setting partnerships}

Because of their concentration on developing new rules and regulations for certain areas or groups of actors, rule-setting partnerships should espouse democratic accountability mechanisms. The traditional field for the application of democratic accountability is the public sector. Rule-setting partnerships assume functions resembling most closely those of the legislative. Parliaments are typically held accountable by a combination of elections, supplementary mechanisms to involve citizens, rules and a system of checks and balances.

Partnerships operate in a very different institutional environment than traditional legislative bodies. Therefore, the mechanisms used to create legislative accountability should not be applied directly to rule-setting partnerships. Rather, legislative accountability mechanisms fulfil various purposes. The accountability arrangements that rule-setting partnerships should adopt do not necessarily have to take the exact same form, but they must achieve the same effects as parliamentary accountability mechanisms.

Legislative accountability pursues two major aims: to give those affected by legislation a say in the decision-making process and to avoid the abuse of 
legislative authority. Individual democratic polities emphasise different elements, but tend to use a common set of mechanisms to achieve these ends.

To achieve the inclusion of citizens in the legislative process, most democratic countries rely on regular parliamentary elections, as well as elements of direct democracy. Supplementary accountability mechanisms strengthen the provision of information to citizens, for example through transparent governance processes, the work of the media and the opposition. Another set of supplementary tools provides citizens with additional means to articulate their interests. They include official consultation processes, opinion polls, interpretations of the 'public mood' created by the media, as well as interest groups, protests, lobby activities, petitions and the use of public complaints procedures.

In order to avoid the abuse of legislative authority, democracies typically rely on rules and systems of checks and balances. Constitutional rules, for instance, safeguard fundamental rights and delimit the authority of parliaments. Procedural rules, moreover, determine the formalities and ensure that decisions are taken in a transparent manner. Through checks and balances, both the executive and the judiciary have certain possibilities to control legislative actions. This puts them in a position to prevent or counter potential abuses of legislative authority.

Fulfilling their responsibility to be democratically accountable, rule-setting partnerships should adopt accountability arrangements that are functionally equivalent to legislative accountability. In other words, they should adopt accountability mechanisms that allow for the effective participation of those affected by the rules and that prevent an abuse of the partnership's authority.

\subsubsection{Accountability through participation}

Giving those affected an influence over decision-making processes has long been accepted as a hallmark of democracy. More recently, the principle has also been recognised as important for many organisations working at the trans- or international level, especially those focusing on development. ${ }^{49}$ For organisations defining rules, guidelines or standards, two sets of international standards exist. The International Organization for Standardization (ISO), which is very influential since its standards are often translated into binding rules, has published a guide outlining procedures and participation rules for standard-setting bodies. ${ }^{50}$ Building on this document, but taking the criteria much further, the International Social and Environmental Accreditation and Labelling Alliance (ISEAL) has produced a code of good practice for organisations setting social and environmental standards. ${ }^{51}$

For international organisations and NGOs not involved in setting rules and regulations, similar standards for the inclusion of affected stakeholders have not been defined. Since the practice enjoys great popularity, however, numerous handbooks, 'how-to'-guides and studies on the effectiveness of individual techniques have been published. ${ }^{52}$ 
In the following paragraphs, democratic accountability standards for rule-setting partnerships are proposed. They are either derived from general democratic principles, the ISO and ISEAL codes or draw on broadly accepted practices of participation. The standards cover two main areas: formal avenues for participation and inclusion and the provision and dissemination of information.

\subsubsection{Create formal possibilities for participation and inclusion}

The first and most obvious step for giving those affected a say in the deliberations and decisions of rule-setting partnerships is to create formal avenues for participation. Partnerships can choose between various options of how to include stakeholders. Each model has its own problems and advantages. Which alternative is most effective and best suited to the situation depends, among other factors, on how many groups or individuals need to be included and on how strongly those groups are organised.

As a first alternative, partnerships can include stakeholder representatives in their formal governance structures. The WCD, for example, emphasised the multi-stakeholder composition of its central decision-making bodies. The 12-member commission itself took the most important decisions and approved the text of the report, containing standards and principles for the building of large dams. The commission was selected by a multi-stakeholder working group to represent various stakeholder groups, including governments, project-affected people, NGOs, people's movements, the dam-construction industry, export credit agencies, private investors and the international development community. ${ }^{53}$ Moreover, the commission relied strongly on the WCD Stakeholder Forum as a sounding board and advisory group. This forum was made up of 68 members, including the participants of the original multi-stakeholder workshop, as well as additional members that were granted access to make the forum more inclusive.

Including stakeholders in the decision-making bodies of partnerships strangthens their democratic accountability. Through their direct involvement, stakeholder representatives have immediate control over the outcomes of the rule-setting process. This model corresponds most closely to the traditional democratic paradigm, where citizens tend to elect the members of parliament. Instead of citizens, partnerships include stakeholders. In principle, this appears to be a fitting equivalent since both citizens and stakeholders are those affected by legislation. Moreover, the inclusion of multiple stakeholders is congenial to the idea of partnerships. Many favour this form of governance arrangement precisely because it allows for the involvement of various groups on an equal footing. Finally, this model also offers pragmatic advantages. Because participation is channelled through representatives, the number of individuals involved in the governing bodies stays limited. This means that decision-making processes remain manageable, both logistically and financially. 
At the same time, however, the inclusion of stakeholder representatives raises a number of serious problems. In traditional democratic polities, citizens tend to be clearly defined as all individuals of a certain age holding the country's nationality. ${ }^{54}$ Stakeholder groups, by contrast, have to be defined individually for each project or organisation. ${ }^{55}$ This raises the critical question of who is recognised as a stakeholder and who takes this decision. The WCD, for example, while renowned for its high degree of democratic legitimacy, has been criticised for disregarding women and populations living downstream of dams as significant stakeholder groups. ${ }^{56}$

Another basic democratic principle that can turn problematic when applied to 'stakeholder democracy' is the 'one person, one vote' rule. Should all stakeholder groups have an equal number of representatives? If not, which criteria should be applied to weigh the influence of individual groups? Their size? The degree to which they are influenced by the rules? This is another aspect that was criticised about the work of the WCD. It operated on the assumption that all identified stakeholder interests should be treated as equally important and legitimate. Klaus Dingwerth sees this as a general problem of stakeholder approaches: 'the stakeholder rhetoric, by conceptually leveling the interests of individuals or groups with different qualities of affectedness, conceals that not all interests are necessarily equally legitimate' (Dingwerth, 2005, p. 75).

A third problem relates to the question of how stakeholder representatives are selected and how they can be made accountable to their stakeholder groups. A relatively small multi-stakeholder working group, for example, selected the commission members of the WCD. In addition, they were asked to serve in a personal capacity, rather than as representatives of their organisations. The commission members were therefore not accountable to broader stakeholder groups. ${ }^{57}$ Another partnership with a multi-stakeholder board is the Global Fund. It has a fixed allocation of seats for various stakeholder groups. Each constituency is responsible for selecting its representative and can freely determine the process for doing so. Where stakeholder groups are well defined and well organised, this can create a democratically acceptable selection process. It is equally possible, however, that individual actors who have little accountability to the other members dominate stakeholder groups.

Considering these opportunities and potential pitfalls, partnerships including stakeholder representatives in their governing bodies should comply with the following standards:

- Provide stakeholder representatives with real decision-making power. Partnerships choosing to include stakeholder representatives in their governing bodies should involve them in the committees that take decisions relating to rules, norms and standards. If this is not the case and stakeholders are only included in consultative fora, partnerships have to 
deal with problems of stakeholder selection and representation without reaping the democratic benefit of granting stakeholders immediate control over outcomes.

- Adopt a considered definition of relevant stakeholder groups that remains open to review. Determining which groups should and which should not be represented in a partnership is always difficult. To optimise their approach, partnerships should go through a carefully designed stakeholder identification process. This involves mapping all those groups and individuals that have an important input to make and that are significantly affected by the partnership's work. ${ }^{58}$ Representatives of these groups should be invited to participate. Crucially, partnerships should also have a transparent process for reconsidering their stakeholder composition. Thus non-participating stakeholders should be able to state their stake and demand representation. The partnership should have a clear process and criteria for deciding on such applications.

- Determine the relative weight of the different stakeholder groups depending on the legitimacy of their interests and their size. The task of determining how many votes or representatives each stakeholder group should have is even more difficult than the process of stakeholder identification. To ensure their democratic accountability, partnerships should not take this decision purely based on the degree of power held by the various groups. Instead, they should consider the groups' degree of affectedness, the legitimacy of their interests and the number of individuals they involve.

- Follow basic democratic principles when selecting stakeholder representatives. Another important aspect of democratic accountability relates to the method for choosing stakeholder representatives. An appropriate procedure needs to meet several requirements. Firstly, the stakeholder groups should be able to select their representatives themselves. Secondly, the groups should hold periodic elections with an open nomination process to choose their representatives. ${ }^{59}$ Finally, the representatives should regularly report back to their constituencies and solicit their inputs on current issues and decisions.

A second possibility for enhancing participation is to conduct formal consultation processes with stakeholder groups. Irrespective of the composition of their governance bodies, partnerships can solicit the inputs of relevant stakeholders while devising their work procedures, when defining rules or standards or when revising them.

Of the case examples discussed above, ICANN has developed comparatively refined consultative techniques. Thus, for example, a task force usually oversees each process of rule development or revision. One of the principal missions of the task forces is to gather information on the positions of relevant constituencies. Once a draft version of the new regulation exists, ICANN routinely gives public notice and allows for a comments period. Whenever 
possible, it also holds public fora to discuss new policies. Moreover, special consultations are conducted with organised constituencies, like, for example, the Government Advisory Committee, which gets involved when issues relating to public policy are at stake.

Formal consultations have distinct advantages as tools to enhance participation. In contrast to the inclusion of stakeholder representatives in governing bodies, they allow for the involvement of a large group of individuals and organisations. This enables partnerships to design their participatory processes in an open manner. As a result, groups overlooked in the stakeholder identification process are not permanently excluded but can contribute to the partnership at a later stage. Moreover, individual stakeholders can voice their positions and interests directly. Any complications related to differences within stakeholder groups, the selection of stakeholder representatives and their accountability to their constituencies can thus be avoided.

But consultations also have their downsides. One set of problems is linked to the lack of control over who gets engaged in consultations. Important stakeholder groups may, for example, find it difficult to get access to the necessary information about the process. ${ }^{60}$ In addition, strongly affected groups may lack the necessary skills and resources to articulate their concerns and interests effectively. The risk is that few powerful, well-organised and vocal actors dominate the process. ${ }^{61}$

Another set of potential problems stems from the uncertainty of how the inputs will be used. Organisations holding consultations may use them as a sham to create a semblance of democratic legitimacy. Rather than seriously considering all contributions, these organisations may be tempted to ignore inputs or to selectively use only those reaffirming their original positions. ${ }^{62}$ Poorly designed consultative processes that lack credibility may therefore fail to create democratic accountability as well as the ownership among stakeholders that is necessary to achieve voluntary compliance with the proposed rules.

Rule-setting partnerships can opt for consultations as their preferred method of participation or complement the inclusion of stakeholder representatives in governance structures through formal consultations. To design consultative processes in an effective and legitimate way, partnerships should adhere to the following principles:

- Use an open consultation process. Partnerships can use a broad range of consultative techniques. They range from written questionnaires and comments procedures for new policies to online discussion fora and in-person meetings or workshops. ${ }^{63}$ Irrespective of which technique is chosen, partnerships should design the process in an open manner, enabling the participation of all interested parties. Thus, for example, questionnaires used to gather information about the positions of different stakeholder groups should not only be sent to a predetermined set of stakeholders but should also be available for other interested parties. 
- Disseminate information about the issues addressed as well as the possibilities for submitting contributions widely. This is an important precondition for ensuring broad participation. The dissemination effort should contain two elements. Firstly, partnerships should identify relevant stakeholders and contact them directly. Secondly, they should openly publish information through as many appropriate channels as possible. Depending on the circumstances and the types of stakeholders involved, this may include prominent postings on the partnership's website, on newsletters and websites of thematically related organisations, in relevant publications, the media or on local notice boards. ${ }^{64}$

- Open several consultation channels simultaneously to further increase the number of stakeholders involved. A range of different consultation techniques was mentioned above. These methods can reach diverse audiences and can encourage contributions of differing quality. By using several consultation channels at the same time, partnerships can broaden the scope of both participation and types of submissions. Thus, for example, a partnership may at first hold personal meetings to determine whether and where new standards or rules are necessary. It may then distribute questionnaires among a wider group of stakeholders in order to collect information about their positions. Finally, it may open drafts of the rules to public comments.

- Select consultation techniques suited to the needs and skills of key stakeholder groups. When selecting avenues for consultation, partnerships should bear in mind that stakeholder groups can have very different resources and skills at their disposal. Partnerships should tailor their consultation methods to the capacities of important stakeholder groups. This can become relevant, for example, for determining the languages used, for choosing between verbal or written and electronic or non-electronic means of communication.

- Ensure a balanced representation of interests by supporting disadvantaged groups. In addition to choosing their consultation methods according to the needs of important stakeholders, partnerships should take measures to facilitate the participation of disadvantaged groups or individuals. Disadvantaged stakeholders are those lacking the resources or skills needed to make their voices heard. NGOs in developing countries may, for example, not be able to cover the travel costs for participating in international meetings and may have difficulties in gaining access to relevant knowledge. Within communities, women or certain minorities may find it hard to speak out. Depending on the identity of the disadvantaged groups, assistance can range from financial support and capacity building to the use of facilitation tools designed to achieve equal participation. ${ }^{65}$

- Give contributions due and equal consideration and deal with them in a transparent manner. Once partnerships have achieved broad and balanced participation, they have to handle the inputs they receive appropriately. 
This implies firstly that partnerships treat submissions as objectively as possible. Secondly, it entails that partnerships either integrate the proposals in their work or provide a justification and explanation for why they were not taken into account. ${ }^{66}$ Thirdly, partnerships should be transparent in this process. A good way to create transparency is to create a collection or summary containing all contributions together with the partnership's reactions. This document should be freely accessible to all interested parties, for example by posting it on the partnership's website.

Finally, partnerships can strengthen participation by establishing permanent mechanisms that allow interested parties to raise issues or voice concerns. In this case, partnerships do not actively solicit inputs during the rule-making process. Instead, stakeholders can act on their own initiative and trigger debates or certain policy procedures. Permanent complaints and comments mechanisms are a good complement to the active involvement of stakeholders in partnership activities. On their own, however, they are not sufficient for creating an adequate level of democratic accountability for rule-setting partnerships.

There is a variety of tools and institutional features providing stakeholders with the opportunity to articulate their concerns and preferences. In addition to its other elaborate channels for participation, ICANN, for example, has instituted several mechanisms to deal with stakeholder complaints. This includes a reconsideration policy, an independent review policy and the office of an ombudsman. ${ }^{67}$ Thus anybody materially affected by an ICANN action can request the ICANN board to reconsider this action. A special board committee decides within 30 days whether or not it accepts the request and is obliged to justify any rejections. Within 90 days, the committee should forward its final recommendation to the board. All reconsideration requests and subsequent decisions are published on ICANN's website. The independent review policy covers instances when actions by ICANN or its staff are deemed inconsistent with its articles of incorporation or by-laws. An independent international arbitrator handles these complaints. Finally, ICANN has an ombudsman who deals with any disputes not covered by the other two mechanisms. The mission of the ombudsman is to resolve conflicts informally, relying, for example, on negotiations, facilitation or 'shuttle diplomacy'. Other procedures common in many democratic polities, though not applied by any of the partnerships discussed as case examples here, include formal petitions as well as the possibility to introduce draft norms to the rule-setting process. ${ }^{68}$

Open comments and complaints procedures create important benefits in terms of democratic accountability: They are usually open to contributions from all interested parties and they allow stakeholders to decide when and on what they want to comment. Thus they complement both main alternatives for the inclusion of stakeholders well. They enhance the democratic 
accountability of partnerships including stakeholder representatives in their governing bodies because they enable all stakeholders, including those that may not have representation, to voice their interests and concerns directly. Partnerships relying on stakeholder consultations often have access to a broader group of interested parties, but they tend to solicit their inputs on very specific questions. Open comments and complaints procedures can strengthen democratic accountability here by broadening both the scope of issues open for comment and the time frame for submitting contributions. Due to these benefits, both ISO guide 59 and the ISEAL code of good practice for standard-setting organisations recommend the institutionalisation of comments and complaints mechanisms. ${ }^{69}$

At the same time, however, open comments and complaints procedures face strong limitations as instruments of democratic accountability. Firstly, the contributions received are very unlikely to provide a representative picture of the different stakeholder interests relating to any specific issue. Since interested parties submit comments on their own initiative, a systematic collection of viewpoints on a specific issue does not usually take place. Moreover, it is very likely that well-informed, well-resourced and vocal interests dominate these open comment mechanisms. Lack of control over who gets involved was already mentioned as a problem in stakeholder consultations. It is strongly exacerbated in open comments and complaints procedures, however, since they usually do not involve any process of stakeholder identification or proactive outreach to disadvantaged groups.

A second problem relates to the effectiveness of comments or complaints in generating changes. Many institutions inviting open comments do not clarify how these inputs are treated. And even where a procedure is defined, such as the right to receive a reply that is guaranteed by various European institutions, the influence of comments on the policy process may remain unclear. As a result, open comments and complaints procedures easily lack credibility and stakeholders may not have sufficient incentives for using these avenues for participation. Therefore, open comments and complaints procedures cannot generate appropriate democratic accountability if used on their own. In conjunction with other participatory techniques, however, they can be beneficial.

To reap the benefits of open comments and complaints procedures while avoiding their pitfalls, partnerships should adhere to the following related principles:

- Generate possibilities for submitting open comments and complaints as a complement to other procedures for participation. Rule-setting partnerships should allow for continuous comments relating to any aspect of their work. These comments and complaints procedures should, however, only be used as a complement and not as an alternative for other means of participation. 
- Broadly disseminate information on how and when interested parties can comment or complain. Open comments and complaints procedures do not usually allow partnerships to actively identify and contact relevant stakeholder groups. To encourage widespread use of the mechanisms and increase the representative nature of submissions, partnerships should as a minimum explain clearly how the comments and complaints procedures work. This information should be made easily accessible to all interested parties.

- Use open comments and complaints to raise issues, rather than as a decision-making procedure. As discussed above, it is very difficult, if not impossible, to receive a representative sample of stakeholder views through open comments and complaints. The main function of comments and complaints procedures should therefore be agenda setting. Issues raised by interested parties should then be discussed and resolved with the help of other, more representative, participatory tools.

- Define a procedure for dealing with comments or complaints. To make their comments and complaints procedures credible, partnerships should have a clear process for handling contributions. This process should provide some guarantee that legitimate inputs are treated properly, while allowing partnerships to reject insincere or immaterial comments. As a minimum, everybody submitting a comment or complaint should be granted the right to receive a reply outlining how the partnership will deal with the submission or justifying why the contribution is rejected.

- Ensure transparency in dealing with comments and complaints. Finally, to further strengthen the credibility of the process, partnerships should handle comments and complaints in a transparent way. This entails firstly that the procedures for managing comments and complaints are clearly defined and easily accessible to all interested parties. Secondly, it involves collecting and regularly publishing the inputs received as well as the corresponding reactions.

\subsubsection{Provide stakeholders with relevant information, knowledge and skills}

Transparency has repeatedly been discussed in this book as an essential ingredient for any type of accountability. Following the basic model of accountability outlined in section 2.2.1, access to relevant information is crucial because it enables principals to evaluate the behaviour of their agents. For a different reason, transparency is once more key at this juncture. Democratic accountability, it was argued above, is to an important degree about giving those affected a say in the rule-making process. Effective stakeholder participation, however, cannot be guaranteed solely by instituting formal possibilities for participation. Stakeholders are only able to execute their rights and provide meaningful inputs if they are equipped with the necessary information, knowledge and skills. 
In his frequently quoted and powerful words, James Madison describes the importance of knowledge for democratic government as follows:

A popular Government, without popular information, or the means of acquiring it, is but a Prologue to a Farce or a Tragedy; or, perhaps both. Knowledge will forever govern ignorance: And a people who mean to be their own Governors, must arm themselves with the power which knowledge gives.

(Hunt, 1900-10, Vol. 1, Chap. 18, Doc. 35) ${ }^{70}$

Organisations like Privacy International, which runs a major campaign for freedom of information legislation, emphasise the link between access to information and the ability to participate:

Democracy is based on the consent of the citizens and that consent turns on the government informing citizens about their activities and recognizing the right to participate. The public is only truly able to participate in the democratic process when they have information about the activities and policies of the government.

(Banisar, 2006, p. 6)

Because of its centrality to both accountability in general and to participation, transparency has become a very broadly recognised standard of democratic governance. Thus, for instance, the Universal Declaration of Human Rights and the International Covenant on Civil and Political Rights recognise the right to seek, receive and impart information. ${ }^{71}$ Moreover, the UN Convention against Corruption requires governments to take measures to enhance the transparency of their public administration and the Rio Declaration demands access to environmental information to enable participation. ${ }^{72}$ The importance of transparency is also increasingly reflected in government practice. Thus by 200670 countries from across the globe had adopted comprehensive freedom of information legislation, while another 50 were in the process of developing it. ${ }^{73}$

Consequently, the codes defining governance norms for standard-setting organisations also emphasise transparency. Both, ISO guide 59 and the ISEAL code of good practice, demand that standard-setting organisations publish their future work programmes or notify stakeholders of upcoming decisions, make available copies of the draft standards, publish approved standards promptly and document the process of standard development. Beyond that, ISEAL proposes that organisations publish all received comments, as well as the ensuing reactions and that they create a dedicated focal point for enquiries to facilitate the provision of information. ${ }^{74}$

As discussed in section 2.2.2.4, as well as in section 4.2.3, transparency can concern many different aspects of an organisation. Several of these areas are 
relevant in the context of participation. For stakeholders to be able to deliver meaningful inputs, they need sufficient information about the rule-setting process, including the schedule of planned activities and the procedures for submitting contributions, as well as the subject matter under consideration. To strengthen the credibility of the process, two further elements of transparency are instrumental. Firstly, organisations should handle submissions in a transparent way so that stakeholders know how their contributions influence the rule-setting process. Secondly, transparency on their financial sources can help address potential concerns about a partnership's independence and objectivity.

Organisations can take very different steps to create transparency. Which activities are required to generate an adequate level of transparency depends on the nature of the stakeholders involved. In the case of ICANN, for example, affected stakeholders are by definition engaged in activities related to the Internet. Therefore, it seems appropriate for ICANN to rely mainly on electronic means of communication to publish and disseminate relevant information. For partnerships dealing with well-organised and well-informed stakeholders, moreover, a relatively passive approach to information dissemination may be sufficient. EITI, for instance, predominantly addresses multinational companies active in the extractive industries that have a strong interest in and awareness of international norm-setting processes. The WCD, by contrast, faced different requirements. Among its key stakeholders were local communities affected by dam-building projects. To inform them and encourage their participation, on-site meetings, non-electronic communication, active outreach, capacity building and the use of local languages were essential.

This dependence on context makes it difficult to establish general standards relating to the concrete modalities necessary for generating appropriate levels of transparency. Nevertheless rule-setting partnerships should respect the following principles to create the conditions for effective participation:

- Provide and disseminate information about the rule-setting process, the procedures for participating, the subject matter under consideration, the way contributions are dealt with and the partnership's financial sources.

- Choose the format and language for providing and disseminating information depending on the needs and capacities of key stakeholders. A basic starting point for partnerships is to publish relevant information online. In many cases, however, information will have to be available in several languages and may require the use of non-electronic forms of communication.

- Where necessary, reach out actively to disadvantaged stakeholders and provide them with training and capacity building. As described in the previous section, measures to support disadvantaged stakeholder groups may include the organisation of separate meetings, capacity building, mandated representation or the use of levelling techniques in facilitation. 
- Respond appropriately to inquiries from third parties. Partnerships should be prepared to make information available in response to inquiries from interested parties. To do so in an appropriate way, partnerships should have an agreed information policy, which defines, where necessary, legitimate confidentiality areas. They should also respond to inquiries in a timely manner.

\subsubsection{Accountability to avoid the abuse of authority}

Parliamentary accountability mechanisms, it was argued above, aim not only at allowing affected parties a say in the norm-setting process but also seek to prevent the abuse of legislative authority. For that purpose, democracies have devised a range of different mechanisms. Citizens can use their right to vote to replace parliaments abusing their authority. Constitutional rules limit parliamentary authority and protect basic rights. These rules can usually not be changed through a simple parliamentary act but require popular referenda or supermajorities. Systems of checks and balances, moreover, enable other governmental bodies to control legislative action. Most importantly, the judiciary can use the process of judicial review to determine the constitutionality and rule conformity of legislative acts. Depending on the political system, the executive can also play an important role in exercising political oversight, for example through its right of veto or its authority to dissolve the parliament.

Compared to the complex institutional set-up of democratic governments, the rule-setting partnerships analysed here have adopted only few similar accountability mechanisms. In many cases, partnership boards take the final decision on new or amended rules. The procedures for selecting partnership boards vary, but rarely include fully democratic elections. Thus, for example, the stakeholder council formally appoints the GRI board. The council, however, can only accept or reject a slate of candidates proposed by a nominating committee, which contains a majority of board members. ICANN used to conduct general elections for its board but now relies on a nominating committee and a fixed stakeholder composition.

In some of the case examples, the partnerships are also able to unilaterally change their mandates and authorities. GRI's board, for example, can amend the partnership's articles of association with a two-thirds majority. The WCD, by contrast, had its mandate clearly defined by an initial stakeholder workshop. Similarly, ICANN cannot autonomously change its constitutional documents, since they are contained in a contract with the US-American government.

The weakest point, however, relates to the partnerships' systems of checks and balances. In the case examples, power is often strongly concentrated. The authority to adopt rules, for example, is in most cases invested in a single body, be it the board, a meeting of partners or a multi-stakeholder committee. ICANN is the only exception here. It has a policy that is similar to judicial review. Through its independent review process, an external 
arbitrator can establish whether or not actions taken by the partnership are consistent with its by-laws and articles of incorporation.

Should it be a cause for concern if rule-setting partnerships do not match most institutional features of parliamentary accountability? In answering this question, we have to distinguish between various levels of accountability and between two kinds of rule-setting partnerships. Firstly, it was established in the first section of this chapter that all partnerships need to fulfil certain minimum requirements for their governance and internal control structures. These provide a basic protection against the abuse of authority and all rule-setting partnerships have to comply with them. Secondly, it was argued that the accountability arrangements espoused by rule-setting partnerships do not have to be identical, but should be functionally equivalent to democratic accountability mechanisms. What functional equivalence entails in this context, however, strongly depends on the potential of organisations to abuse their legislative authority. In this respect, there is a significant difference between institutions that can pass binding rules and those that can only propose voluntary rules. The standards defined in the following paragraphs therefore distinguish between these two cases.

\subsubsection{Partnerships proposing voluntary rules: No additional measures are necessary}

Parliaments have the authority to set rules that are binding for all those within the jurisdiction of the state. These rules are usually not only binding in theory but can be enforced by the judiciary and executive branches of government. Most rule-setting partnerships, by contrast, only have the authority to propose non-binding rules. They rely on voluntary compliance and are not linked to strong enforcement mechanisms. The Voluntary Principles on Security and Human Rights, for example, already contain their voluntary nature in their title. Both governments and companies can decide freely whether or not they want to join the initiative. Once they have subscribed to the principles, all participants commit to promoting the principles and to reporting publicly on the activities undertaken in their support. Similarly, the transparency principles and templates proposed by EITI are adopted voluntarily by governments and companies involved in the extractive industries. By comparison, the standards developed by the WCD enjoy greater authority. They have become a reference point for many debates and decisions relating to the construction of large dams. ${ }^{75}$ The standards, however, derive their authority mainly from the comprehensive and inclusive process that led to their development. Formally, any acceptance of the standards is entirely voluntary.

Partnerships developing voluntary rules, though, can hardly abuse their legislative authority. Stakeholders concerned about the process of rule development or the content of the proposed rules can always reject them. Should, for example, GRI proclaim new standards in an area unrelated to sustainability 
reporting or should those norms violate basic rights, affected parties can withhold their ex-post authorisation and refuse to comply with the rules. The stakeholders of partnerships setting voluntary rules thus enjoy automatic protection against the abuse of legislative authority. Therefore, there is no need for these partnerships to adopt additional measures to achieve functional equivalence with parliamentary accountability.

\subsubsection{Partnerships setting binding rules: Authorisation, mandate, judicial review}

While most partnerships define voluntary rules, some are in a position to set norms with a binding character. This can be the case, for example, where stakeholders depend strongly on a partnership. The dependence can be created through financial links, strong power asymmetries or through the necessity of working with one common system of rules. Partnerships can also be authorised by the relevant authorities to take binding decisions. In classical corporatist arrangements, for instance, partnerships can define rules relating to labour.

Among the case examples, ICANN is the only partnership asserting that its rules are binding. As an analyst puts it:

ICANN, in short, was both asserting control over the design of the name space and imposing constraints on people using that space. ICANN's exercise of authority looked, walked, and quacked like public regulatory power.

(Weinberg, 2000, p. 217)

ICANN was created through an agreement with the US government. As such, it lacks appropriate authorisation for issuing policies and rules that are binding for the entire Internet community. Its stipulations also lack the backing of a compulsory enforcement system. But the nature of its task provides its decisions with strong authority. ICANN regulates the definition and assignment of Internet domain names and ensures that each name is linked to a unique IP address. This is a condition for the smooth functioning of the Internet. ${ }^{76}$ In theory, other organisations could set up domain name registers outside the realm of ICANN. Yet this would undermine the functioning of the entire system. In actual practice, ICANN's policies and rules therefore enjoy a strongly binding character. ${ }^{77}$

Where partnerships set rules with a strongly binding character, stakeholders do not enjoy automatic protection from a potential abuse of legislative authority. Additional accountability measures akin to those used for parliaments or independent regulatory agencies are therefore necessary: ${ }^{78}$

- Achieve appropriate and revocable authorisation for the partnership. Partnerships with the power to set binding rules should derive their 
authority from appropriate external bodies. For partnerships active at the international level, appropriate authorisation can either be granted by intergovernmental bodies or by affected stakeholders. In either case, the delegating body should be in a position to revoke or renew its authorisation. For intergovernmental organisations this entails retaining the right to withdraw the authorisation and entrust another organisation with the task. Where stakeholders delegate the necessary authority directly, they should either make up the rule-setting body themselves or periodically elect its members.

- Define a clear mandate delimiting the partnership's authority. Rulesetting partnerships should have mandates that spell out clearly where the partnership has authority and where it does not. It is also important that the mandate cannot be changed unilaterally by the partnership. The first definition as well as any significant changes of the mandate should require the consent of the relevant authorising bodies.

- Partnership activities should be subject to a process of judicial review. Finally, allegations that a partnership violates its mandate or critical procedural rules should be subject to authoritative review by an independent body. All interested parties should be able to submit cases, at least if their concerns can be shown to be substantial. This also makes it necessary to devise a reasonable way to deal with the costs arising from the procedure so that they do not constitute a material barrier against bringing cases. To be effective, the independent arbitrator or review panel should also be in a position to pass final and binding decisions on the matters referred to it.

\subsubsection{Summary of standards}

Table 5.2 provides an overview of relevant accountability standards for rule setting and regulation partnerships.

Table 5.2 Accountability standards for rule setting and regulation partnerships

\begin{tabular}{|c|c|c|}
\hline $\begin{array}{l}\text { Accountability } \\
\text { principles }\end{array}$ & $\begin{array}{l}\text { Accountability } \\
\text { standards }\end{array}$ & Practical steps \\
\hline \multirow{4}{*}{$\begin{array}{l}\text { Democratic } \\
\text { accountability } \\
\text { through } \\
\text { participation }\end{array}$} & \multirow{4}{*}{$\begin{array}{l}\text { Formal possibilities } \\
\text { for participation } \\
\text { alternative }(a) \text { : } \\
\text { include stakeholder } \\
\text { representatives in } \\
\text { decision-making } \\
\text { bodies }\end{array}$} & $\begin{array}{l}\text { Provide stakeholder representatives } \\
\text { with real decision-making power }\end{array}$ \\
\hline & & $\begin{array}{l}\text { Adopt a considered definition of } \\
\text { relevant stakeholder groups that } \\
\text { remains open to review }\end{array}$ \\
\hline & & $\begin{array}{l}\text { Determine the weight of stakeholder } \\
\text { groups depending on the legitimacy of } \\
\text { their interests and their size }\end{array}$ \\
\hline & & $\begin{array}{l}\text { Follow basic democratic principles } \\
\text { when selecting stakeholder } \\
\text { representatives }\end{array}$ \\
\hline
\end{tabular}


Table 5.2 Continued

\begin{tabular}{|c|c|c|}
\hline $\begin{array}{l}\text { Accountability } \\
\text { principles }\end{array}$ & $\begin{array}{l}\text { Accountability } \\
\text { standards }\end{array}$ & Practical steps \\
\hline & $\begin{array}{l}\text { formal possibilities } \\
\text { for participation } \\
\text { alternative (b): } \\
\text { conduct stakeholder } \\
\text { consultation } \\
\text { processes }\end{array}$ & $\begin{array}{l}\text { Use an open consultation process } \\
\text { Widely disseminate information about } \\
\text { issues addressed and possibilities for } \\
\text { submitting contributions } \\
\text { Open several consultation channels } \\
\text { simultaneously } \\
\text { Select consultation techniques } \\
\text { suited to the needs and skills of key } \\
\text { stakeholder groups } \\
\text { Ensure a balanced representation of } \\
\text { interests by supporting disadvantaged } \\
\text { groups } \\
\text { Give contributions due and equal } \\
\text { consideration and deal with them in a } \\
\text { transparent manner }\end{array}$ \\
\hline & $\begin{array}{l}\text { Formal possibilities } \\
\text { for participation } \\
\text { supplement: } \\
\text { establish permanent } \\
\text { comments and } \\
\text { complaints } \\
\text { procedures }\end{array}$ & $\begin{array}{l}\text { Establish comment and complaints } \\
\text { procedures as a complement to other } \\
\text { participatory mechanisms } \\
\text { Broadly disseminate information on } \\
\text { how and when to use the comment or } \\
\text { complaints procedures } \\
\text { Use comments and complaints to raise } \\
\text { issues, rather than to settle them } \\
\text { Specify a process for dealing with } \\
\text { comments or complaints, including } \\
\text { at least a guaranteed formal reply to all } \\
\text { submissions } \\
\text { Ensure transparency in dealing with } \\
\text { comments and complaints }\end{array}$ \\
\hline & Transparency & $\begin{array}{l}\text { Create transparency relating to rule- } \\
\text { setting process, the procedures for } \\
\text { participating, the subject matter under } \\
\text { consideration, the way contributions } \\
\text { are dealt with and the partnership's } \\
\text { financial sources } \\
\text { Choose the format and language } \\
\text { for providing and disseminating } \\
\text { information depending on the needs } \\
\text { and capacities of stakeholders } \\
\text { Where necessary, reach out actively } \\
\text { to disadvantaged stakeholders and } \\
\text { provide them with training and } \\
\text { capacity building } \\
\text { Respond appropriately to inquiries } \\
\text { from interested parties }\end{array}$ \\
\hline
\end{tabular}


Table 5.2 Continued

\begin{tabular}{|c|c|c|}
\hline $\begin{array}{l}\text { Accountability } \\
\text { principles }\end{array}$ & $\begin{array}{l}\text { Accountability } \\
\text { standards }\end{array}$ & Practical steps \\
\hline \multirow[t]{4}{*}{$\begin{array}{l}\text { Democratic } \\
\text { accountability to } \\
\text { avoid the abuse of } \\
\text { authority }\end{array}$} & $\begin{array}{l}\text { Partnerships setting } \\
\text { voluntary rules } \\
\text { need no additional } \\
\text { accountability }\end{array}$ & $\begin{array}{l}\text { Stakeholders enjoy automatic } \\
\text { protection against the abuse of } \\
\text { legislative authority through their right } \\
\text { to reject rules }\end{array}$ \\
\hline & \multirow{3}{*}{$\begin{array}{l}\text { Partnerships setting } \\
\text { binding rules do } \\
\text { need additional } \\
\text { accountability } \\
\text { measures }\end{array}$} & $\begin{array}{l}\text { Achieve appropriate and revocable } \\
\text { authorisation for the partnership }\end{array}$ \\
\hline & & $\begin{array}{l}\text { Define a clear mandate, delimiting the } \\
\text { partnership's authority }\end{array}$ \\
\hline & & $\begin{array}{l}\text { Subject partnership activities to a } \\
\text { process of judicial review }\end{array}$ \\
\hline
\end{tabular}

\subsection{Standards for implementation partnerships}

A third group of partnerships identified among the case examples focuses directly on policy implementation. The term 'implementation partnership' sometimes generates confusion because almost all partnerships engage in some form of implementation. Partnerships typically set their agendas, develop policies and then seek to implement them. The label for this group of partnerships, however, does not refer to the partnerships' internal processes. Rather, it describes which part of the global policy cycle the partnerships seek to contribute to. ${ }^{79}$ In this context, implementation partnerships differ from the partnerships described thus far. Advocacy and awareness-raising partnerships seek to influence how a policy problem is defined and how central it is on the political agenda. Rule-setting partnerships add to the decision and policymaking stage. Implementation partnerships, by contrast, seek to support the implementation of set policies by contributing necessary resources.

Implementation partnerships thus have to mobilise substantial resources beyond those needed to finance their own core operations. During the financial year 2006, for example, GAIN received over US\$7.6 million in donations, GAVI received US\$250 million, Stop TB had an income of US\$42 million and for the Global Fund, pledges worth over two billion US dollars were due in 2006. These partnerships all focus on public health problems - a comparatively non-controversial and highly visible policy area. Their main donors are typically governments as well as large corporations or private philanthropic organisations. Governments, for instance, provide most of the resources for the Global Fund, whereas the Gates Foundation is the dominant donor for GAIN and GAVI.

This means that to be successful, implementation partnerships need to achieve the delegation of authority over resources at a very different scale than other partnerships. Donors interested in solving a public policy 
problem usually have many options on how to allocate their resources. Other things being equal, they are likely to spend their funds in the way that is seen as most effective in addressing the problem..$^{80}$ Therefore, implementation partnerships need to demonstrate their efficiency and effectiveness in achieving development outcomes. In addition to the basic forms of accountability required for all partnerships, implementation partnerships should thus emphasise accountability for outcomes. This accountability constellation is depicted in Figure 5.3.

This is not to say that outcome accountability cannot be relevant to other forms of partnerships as well. Since all partnerships depend to some extent on the delegation of authority over resources, it is always beneficial if they can demonstrate efficiency and effectiveness in their operations. Yet the discussion about financial accountability earlier has already shown that the scale of financial contributions matters for defining which accountability standards are appropriate. Creating accountability for outcomes is always costly and often very difficult. Implementation partnerships typically operate with greater resources than other types of partnerships. Moreover, they focus directly on effecting development outcomes so that their work tends to lend itself more easily to measurement and results-based evaluation. The ensuing principles of outcome accountability are therefore only defined as expected standards for implementation partnerships.

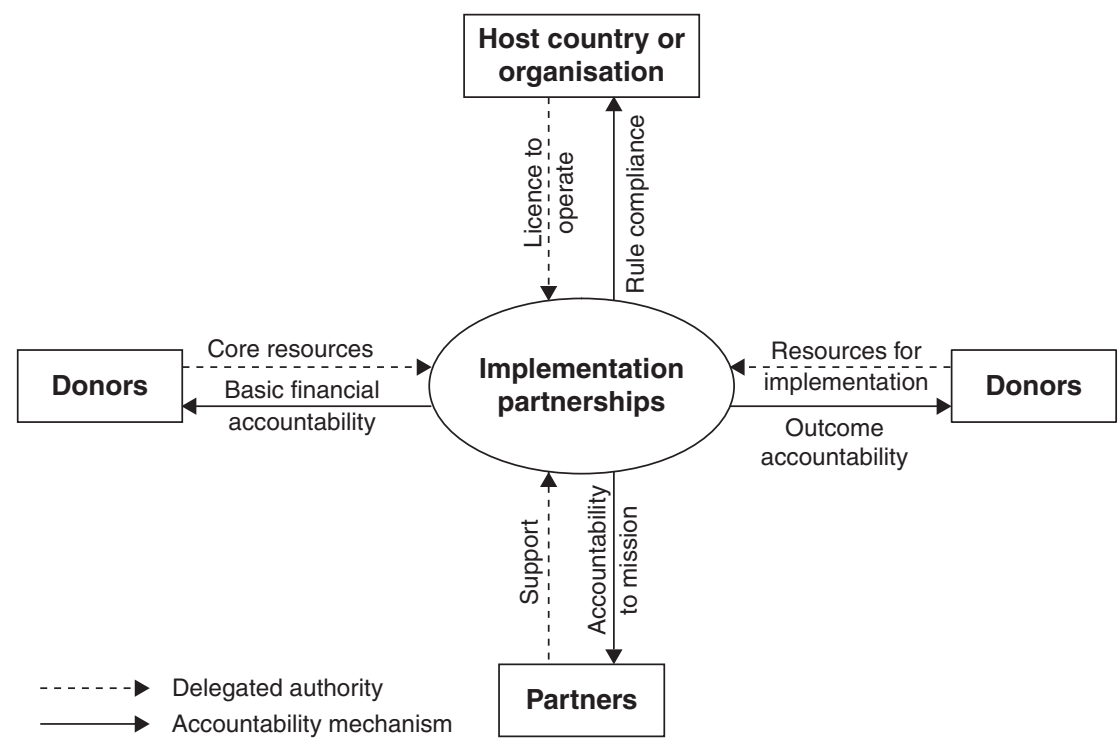

Figure 5.3 Accountability of implementation partnerships 


\subsubsection{Applying corporate accountability standards to partnerships}

Attempts to create or increase accountability for outcomes can be observed in all sectors. The archetypal area of practice for outcome accountability, however, is the corporate sector. Therefore, this section briefly revisits the mechanisms at work in corporate accountability and discusses how these principles can be transferred to implementation partnerships. ${ }^{81}$

Accountability arrangements in corporations focus overwhelmingly on creating accountability for outcomes. This happens at several levels, only some of which an individual company can influence. Firstly, the classical tool for ensuring companies' efficient and effective operations is the market. A well-functioning market is characterised by competition between various providers of similar goods and services and the availability of adequate information about these goods and services. Under these conditions, consumers can choose the products that best suit their needs and that offer the best quality for the relatively lowest price. Since consumption behaviour decides on the economic survival of individual firms, the competition inherent in a functioning market puts companies under continuous pressure to optimise their processes and improve their performance as seen by consumers.

Secondly, the majority of larger companies today are run by professional managers. Owners, who delegate the authority over their resources to managers, have developed a range of mechanisms to make them accountable for performance. These aim either at aligning the interests of managers to those of the owners or at improving the monitoring of managers. The mechanisms include several forms of sanctions and incentives, such as hiring and firing policies, performance-related compensation and the option for owners to sell their stake in the company. They also include tools to improve monitoring by reducing the information asymmetry between owners and managers, for example through strict accounting, reporting and auditing standards as well as the institution of a supervisory board.

In many respects, implementation partnerships work under different circumstances than companies. Firstly, they often provide goods or services for which there is no or a very constrained market. The implementation partnerships among the case examples analysed here, for example, all address public health issues with a focus on developing countries. The partnerships' beneficiaries usually do not have to pay at all or at least not for the full cost of the goods or services they receive. Secondly, implementation partnerships usually do not face competition in the traditional sense. The partnerships were created to fill existing gaps in the provision of goods and services. Often, therefore, there are no or few alternative providers of similar goods and services. And even where various providers coexist, they do not tend to compete for 'customers'. Their ultimate goal is not to make a profit but to provide a public service, and their economic survival depends on the continued commitment of donors, rather than the individual choices of beneficiaries. 
Finally, partnerships usually lack a clearly defined performance measure that would be comparable to a corporation's financial bottom line.

Given these differences, how can corporate accountability standards be applied to partnerships? Over recent years, both public and civil society organisations have experimented with introducing results-focused accountability mechanisms in their work. These experiences have shown that the translation of private sector principles for the public and non-profit sectors faces some inherent limitations. At the same time, however, a range of mechanisms were introduced to strengthen accountability for outcomes. These include a focus on performance evaluations, as well as the introduction of market elements in the provision of public goods and services.

\subsubsection{Outcome accountability through performance evaluation}

Creating accountability for outcomes entails assessing the performance of an organisation or individual against a certain yardstick or measure. ${ }^{82}$ In the corporate sector, a clearly defined, common yardstick exists. No matter what product or service a company offers and no matter which additional objectives individual owners pursue, all companies share one goal. This goal is firstly to ensure the company's economic survival and secondly to maximise profits.

Government agencies, NGOs and partnerships, by contrast, work on a non-profit basis. They may share an interest in institutional survival. Beyond that, however, they have no common or equally clearly defined bottom line. In the words of an analyst commenting on the difficulties involved in assessing the organisational performance of NGOs:

NGOs must contend with the fact that they belong to a category of organisation with no straightforward or uncontested measure of organisational, as distinct from project, effectiveness. In other words [...] non-profits have no readily acknowledged 'bottom line'.

(Fowler, 1995, p. 147) ${ }^{83}$

To build accountability for outcomes, implementation partnerships should nevertheless try to assess their performance. As a first step, this necessitates setting clear goals and targets. As a second step, it requires monitoring performance and linking it to incentives for performance improvement.

\subsubsection{Define clear objectives and performance targets}

Organisations can only evaluate their performance if they have clearly defined organisational objectives that can be translated into measurable performance targets. The implementation partnerships among the case examples all emphasise the definition of goals and targets. Yet they differ both in the clarity of the targets chosen and the level at which performance is evaluated. 
GAIN, for example, set itself the target of reaching one billion people at risk of malnutrition with fortified foods by 2008 and has defined several indicators for tracking organisational performance. ${ }^{84}$ Similarly, Stop TB has committed itself to reaching time-bound targets relating to the diagnosis, treatment and prevention of TB. To date, however, it has not established performance criteria that would indicate how the partnership's activities contribute to reaching these goals. ${ }^{85}$ Similarly, RBM emphasises quantified objectives in the overall fight against malaria without singling out its own contribution to that goal. ${ }^{86}$ GAVI and the Global Fund, by contrast, have defined both overall outcome targets (reflected in performance agreements with recipient countries) and quantified, time-bound performance measures for their own activities. ${ }^{87}$

With the growing popularity of results-based management strategies over recent years, many government agencies and civil society organisations have made first experiences with quantified goals and performance targets. This is especially the case in countries with an Anglo-American background, including the UK, the US, Canada, Ireland, Australia and New Zealand. The introduction of performance measures is particularly popular in policy areas like public health, education, welfare and development. ${ }^{88}$ The effects of these measures are controversial and have generated much academic and political debate. ${ }^{89}$

Analysts have identified several potential problems related to the definition of clear organisational objectives and their translation into measurable performance indicators in the public sector and in civil society organisations. Due to these problems, it is disputed whether or not performance indicators improve efficiency and strengthen accountability for outcomes. ${ }^{90}$

A first problem is that performance measures tend to be simple indicators that can easily fail to reflect the complexity of the issue addressed. Matthew Diller finds this to be the case with the indicators chosen during the welfare reform in the US and believes that the problem is not easy to remedy:

In the new regime that focuses on results, the most visible and quantifiable of outcomes become the most important. [...] While performancebased government may be effective if the goal is defined in terms as simple and unequivocal as caseload reduction, the introduction of caveats and countervailing interests may render it ineffective as a means of establishing central control.

(Diller, 2000, pp. 1183 and 1184)

Secondly, several analysts find that the indicators chosen to measure performance are often not sufficiently clearly related to the organisation's overall goals. Propper and Wilson, for example, cite a study on the effects of the performance measures introduced as part of the US Job Training and Partnership Act of 1982. The study finds that most performance indicators are evaluated on a short-term basis and that as a result, 
the long term added-value goals are not met. Instead, the short-term PMs [performance measures] that are used in their place are either uncorrelated with, or negatively correlated with, long-term value added.

(Propper and Wilson, 2003, p. 257)

Thirdly, as a result of poorly chosen indicators, managers and staff can face perverse incentives. Thus, for example, the focus on standardised school tests may force teachers who are genuinely interested in furthering their students' knowledge, ability to learn and think critically to 'teach to the test' and neglect their broader educational objectives. ${ }^{91}$

Implementation partnerships intent on strengthening their accountability for outcomes should learn from the controversial experiences made in the public sector and in civil society organisations and adhere to the following standards when defining their organisational objectives and performance targets:

- Invest significant efforts into the definition of organisational objectives and performance targets. Experiences with the introduction of performance measures in the public sector and in civil society organisations have shown that poorly chosen performance indicators can be counterproductive. Because of their strong focus on outcome accountability, implementation partnerships must evaluate their performance. In order to avoid the potential problems related to indicator selection, they should, however, be prepared to invest the necessary effort to establish a well-designed system for performance evaluation.

- Demonstrate how performance indicators are linked to and will lead to the achievement of broader organisational objectives. A first crucial requirement is that the indicators chosen are positively correlated to the partnership's goals. Where possible, the indicators should therefore include measures directly assessing changes in the intended outcomes. Moreover, partnerships should establish exactly how their own activities are intended to contribute to the desired goal and develop a strategy for evaluating these activities as well as their effects.

- Involve stakeholders in the definition of goals and indicators. Implementation partnerships typically seek to deliver a good or service to an underserved community. An important aspect of performance is thus to what degree and how partnership activities affect the position or welfare of their target groups. The affected individuals or groups themselves are best placed to establish which elements are most important for their well-being. They should therefore be strongly involved in the definition of performance indicators for implementation partnerships. ${ }^{92}$

- Combine objective and subjective, as well as quantitative and qualitative indicators. To avoid some of the potential counterproductive effects of the introduction of performance measures, partnerships should rely on 
a mix of different kinds of indicators. Thus they should not only rely on objective data, such as a reduction in waiting times or the number of goods delivered, but also on subjective data, such as service satisfaction or individual welfare assessments. To avoid the misinterpretation of quantitative data, moreover, the inclusion of qualitative data collection methods can be very helpful.

\subsubsection{Monitor performance and create incentives for performance improvement}

By establishing clear objectives and performance indicators or targets, organisations create the basis for evaluating their activities and clarify expectations for their behaviour. Following the basic model of accountability proposed in section 2.2.1, creating accountability additionally requires collecting information about the agent's behaviour and defining sanctions and incentives to encourage compliance or improvement. To effectively strengthen their accountability for outcomes, implementation partnerships should therefore monitor performance and create incentives to improve it.

The corporate sector strongly emphasises the necessity of accurate performance measurement and reporting. Especially for publicly traded companies, most relevant aspects relating to accounting, reporting and auditing are strictly regulated. Thus, for example, accountants and auditors have to comply with strict professional norms concerning both their training and the principles they apply. Moreover, most governments have passed legal regulations determining what information has to be recorded, when and how it has to be reported and whether it has to receive independent confirmation. As mentioned earlier, companies and their managers also face manifold incentives for performing well.

In the public and civil society sectors, by contrast, only certain aspects relating to financial accounting and reporting are subject to regulations. For the monitoring and reporting of performance results, no similar rules exist. Those government agencies and NGOs, however, that have determined performance indicators for their work, are also often monitoring and reporting on their performance. Whether and how performance results are linked to sanctions or incentives differs strongly. In some instances, for example, performance data are made public and influence the organisation's reputation. Even if only used internally or shared with donors, though, performance results can have an impact on promotions, on budget developments and the conclusion of new contracts.

Again, analysts have pointed to a number of potential problems and complications that can arise in the context of performance measurement in the public and non-profit sectors. ${ }^{93} \mathrm{~A}$ first risk is that staff and managers manipulate performance data to their own advantage. Courty and Marschke, for example, analyse the phenomenon of 'gaming' in government organisations. They find that when agents strategically report their performance outcomes 
to maximise their awards, this can have a negative impact on the real goals of the organisation (Courty and Marschke, 2004). In addition to gaming, Peter Smith describes how the publication of performance data in the UK tempts officials to misrepresent data (Smith, 1995).

Secondly, researchers have found that a strong focus on quantitative performance targets can inhibit organisational learning. Thus, for instance, Thomas Freeman finds that as performance indicators are used to create external accountability and verification, they can undermine the conditions necessary for quality improvement (Freeman, 2002). Similarly, Alnoor Ebrahim contends that too much accountability can hinder NGOs in achieving their missions. More specifically, his concern is 'about instances of too narrowly focused upward accountability - where donor demands for information are satisfied at the expense of longer-term processes of organizational learning' (Ebrahim, 2005, p. 81).

Finally, performance measurement in the public and non-profit sectors is often confronted with complex technical problems. Relevant reliable and valid data are often difficult to come by. Moreover, in complex policy areas, it can be very hard to establish cause and effect or to measure the impact of an individual organisation on the final outcome. ${ }^{94}$ As Hugo Slim puts it for NGOs:

[T]he current art and science of social and environmental accounting is truly complex on occasion. Accounting for the impact or outcome of NGO work can be uncertain, is usually contested and can border on pure speculation at times as NGOs try to track cause and effect between their actions and the personal, social, economic, environmental and political change around their projects.

(Slim, 2002, p. 4)

For implementation partnerships, these experiences contain the following lessons:

- Consider issues relating to performance measurement already during the planning process and start collecting data early. To assess the impact of partnership (or other organisations') activities on a public policy problem, it is standard practice to compare the actual situation to a counterfactual, that is, to the hypothetical case in which the activities did not take place. ${ }^{95}$ To construct a convincing counterfactual, data describing the situation prior to the intervention are of central importance. Therefore, implementation partnerships should ensure they have access to or should collect relevant data as early as possible.

- Ensure objectivity of data and their presentation. Implementation partnerships can take various steps to reduce the risk of data manipulation and misrepresentation. Firstly, they can try to rely on external sources 
of data, such as independent opinion polls or official statistics. Secondly, they can task independent agencies of good reputation to collect data on their behalf. Thirdly, they should conform to relevant existing rules concerning accounting, reporting and auditing. ${ }^{96}$

- Encourage learning by emphasising positive incentives. Performance evaluations have long been seen to pursue two purposes: creating accountability and encouraging learning. ${ }^{97}$ Where accountability, however, means punishment, ${ }^{98}$ it encourages a risk-averse culture and thus undermines efforts to learn from past experience and improve performance. To overcome the apparent accountability-learning dichotomy, implementation partnerships should involve their staff and managers in the evaluation process and reward good performance rather than simply punishing bad performance. ${ }^{99}$ Moreover, partnerships should avoid giving perverse incentives. This is the case, for example, when current performance is used to determine future performance targets, which effectively punishes good performers.

\subsubsection{Outcome accountability through the introduction of market elements}

In the private sector, functioning markets have two main effects on outcome accountability. Competition creates continuous pressure on companies to enhance the efficiency of their operations. In addition, consumer choice gives individuals a powerful means of expressing their preferences and of indicating which products best fit their needs.

In the public sector, various strategies have been used to introduce market elements in the provision of public goods and services. In some areas, full privatisation is possible. Many governments have privatised formerly public utilities such as the providers of gas, water, electricity or telecommunication services, which share many characteristics of private goods. ${ }^{100}$ In many other areas, however, governments do not consider privatisation a desirable option. ${ }^{101}$ Instead of full privatisation, many governments have tried to introduce alternative means for creating the two effects described above. In order to generate competition, many governments delegate important tasks to private providers, using competitive bidding processes for allocating contracts. ${ }^{102}$ Outsourcing can subject private and public service providers to competitive pressures. Most often, however, beneficiaries cannot make 'consumption choices' on those products and therefore play little or no role in assessing the quality and efficiency of the services provided. To remedy the situation in this context as well as in cases where government agencies continue to act as service providers, governments often employ client satisfaction surveys, recipient focus groups or similar means to collect beneficiary feedback. ${ }^{103}$

What lessons do these experiences hold for implementation partnerships? Full privatisation is usually not a viable alternative for the partnerships under consideration here. Their objective is to contribute to the achievement of 
public policy goals and to deliver goods and services in areas not sufficiently served by governments or companies. On their own, markets are therefore unlikely to generate the desired outcomes. The options for partnerships to increase their outcome accountability through the introduction of market elements thus include outsourcing and the gathering of beneficiary feedback. In both areas, partnerships should take on board the lessons learnt from similar experiences made by the public sector and civil society organisations.

\subsubsection{Outsource suitable tasks through competitive bidding processes}

Implementation partnerships can introduce an element of competition in their work by outsourcing certain tasks to competing providers. Among the case examples, almost all implementation partnerships allocate a significant amount of their resources to third providers. The Global Fund has gone furthest in this respect. It exclusively operates as a financial instrument, providing grants enabling other organisations to implement policies to fight AIDS, tuberculosis and malaria. In its 'performance-based grant making', the Global Fund emphasises results. Thus funding proposals are evaluated by a technical review committee before the board takes decisions; local fund agents assess the financial management and administrative capacities of recipients; success indicators and reporting requirements are agreed with the recipient agency and included in the contract; regular progress reports and audits are conducted on programmes and ongoing disbursements depend on the results of these evaluations. ${ }^{104}$

Analysts and commentators have identified several potential problems related to outsourcing as practised in the public sector. Firstly, they have raised the general concern that the introduction of market-based reforms may undermine traditional forms of governmental legitimacy and accountability. ${ }^{105}$ Partnerships, however, are not naturally endowed with similar levels and types of accountability and legitimacy as governments. It is for this very reason that partnerships have been strongly criticised as a form of public private governance. It has been argued throughout this book that to counter these challenges, partnerships should adopt appropriate accountability mechanisms. For implementation partnerships, it was determined that because of their use and allocation of significant resources, a focus on accountability for outcomes was appropriate. In an answer to this general critique of outsourcing, implementation partnerships should therefore adopt the measures for enhancing outcome accountability discussed in this chapter.

Secondly, empirical studies have found that outsourcing does not necessarily lead to enhanced competition. This can be due to several reasons. Public agencies may not use competitive bidding processes to allocate contracts; where competitive bids are used, they may not attract a sufficient number of submissions to create competition; bids may not be evaluated in a fair manner but be used as a sham for allocating nepotistic contracts; and 
contractors may not really fear sanctions such as losing their contracts as a result of bad performance. ${ }^{106}$

Thirdly, analyses of performance-based contracts used in outsourcing or in agreements with independent government agencies often criticise the way performance is evaluated. The contracts typically define the goals to be pursued by the contractor and specify which indicators will be used to assess performance. Since the chances of gaining future contracts and often the level of compensation for current activities depend on these performance evaluations, indicator targets have great importance for contractors. As discussed in the previous section of this chapter, there is a strong risk that the chosen performance indicators do not reflect all or even the most important aspects of the desired outcomes. Just as deciding on suitable performance indicators is key to establishing outcome accountability for partnership operations generally, it is also crucial for designing functioning performancebased contracts with subcontractors.

Building on the experiences of the public sector, implementation partnerships should pay heed to the following principles when outsourcing parts of their tasks:

- Use competitive and transparent bidding processes to allocate contracts. Outsourcing can only increase the efficiency of partnership operations and enhance accountability for outcomes if it introduces competition in the provision of goods and services. Only contract allocation practices in which potential providers submit offers competing on price as well as the type or quality of services offered are therefore suitable for implementation partnerships.

- Ensure that a sufficient number of bids are submitted. To achieve this partnerships should only consider activity areas for outsourcing in which a number of different potential providers exist. Partnerships should also specify a minimum number of bids (for example, 3 ) required before any contract can be concluded.

- Use a transparent and fair process for evaluating bids and allocating contracts. Where competitive bidding processes are opaque, staff may be influenced by factors not related to the bidding document, including instances of corruption. Partnerships should therefore ensure transparency in dealing with submissions and evaluate bids in an objective and fair manner.

- Define adequate performance indicators to be included in the outsourcing contracts. Implementation partnerships should choose those activity areas for outsourcing where it is comparatively easy to define good performance indicators. Beyond that, partnerships should follow the standards for setting performance indicators outlined in the previous section.

- Link contractor performance to sanctions and incentives. Competitive pressures are only real if contractors have to face the consequences of 
their performance. Where contracts are relatively long-term, partnerships should disburse resources in stages and make further payments dependent on performance. The prospect of new future contracts can also work as a powerful incentive. Work areas requiring ongoing or repeated efforts therefore lend themselves more easily to outsourcing than one-off contracts.

\subsubsection{Collect beneficiary feedback to assess performance}

Another critical contribution of markets to outcome accountability is that they provide consumers with an automatic and powerful avenue for expressing their opinions about products and services. Implementation partnerships, even if they do not operate under market conditions, can simulate this effect by gathering feedback from their clients or beneficiaries. This information can be crucial for assessing the quality of the products and services delivered and for evaluating whether partnership activities meet the needs of their target groups. ${ }^{107}$

Among the case examples, some implementation partnerships are collecting beneficiary and stakeholder feedback when evaluating their own or their contractors' activities. Yet there is much scope for further expanding this practice. One positive example is RBM. When it conducted an intensive external evaluation of its activities in 2002, an important part of the process included interviews with stakeholders in affected countries. ${ }^{108}$ Similarly, the external evaluation conducted for the Stop TB partnership included several interviews with stakeholders and beneficiaries in affected and targeted countries. ${ }^{109}$

Stakeholder interviews enable partnerships or external evaluators to gather focused in-depth information from a relatively broad range of participants. They are, however, comparatively expensive to conduct and are thus rarely used on an ongoing basis. A cheaper alternative with an even broader reach is using client or beneficiary satisfaction surveys. They are used by many companies as well as governments in countries where the introduction of results-based management techniques is advanced, such as Australia, the UK or the US. ${ }^{110}$ Both interviews and surveys, however, have a range of shortcomings. Thus they do not encourage debate or the exchange of information between different stakeholders, they are not suitable for providing ongoing feedback and they tend to strongly predetermine which topics are dealt with. ${ }^{111}$ Another option used by both governments and companies are focus groups. These smaller group discussions allow for a more intensive exchange and give stakeholders a stronger role in setting the agenda. ${ }^{112}$ Finally, many companies and governments have set up permanent complaints mechanisms, such as complaints hotlines or complaints boxes. These encourage all clients or beneficiaries to voice their grievances but are often only used by strongly disaffected or engaged users. ${ }^{113}$

This brief discussion shows that each specific technique for gathering beneficiary feedback has its distinct advantages and problems. To provide 
useful input to an assessment of the partnership's performance, feedback mechanisms should include information from diverse relevant sources and generate an accurate picture of beneficiary perceptions and opinions. ${ }^{114}$ To achieve this, implementation partnerships should adhere to the following principles when designing feedback mechanisms for beneficiaries:

- Routinely gather information about beneficiary satisfaction and preferences. The implementation partnerships analysed as case examples here have mainly conducted stakeholder interviews as one-off or very irregular exercises. To engage in continuous quality improvement and to adapt their products and services to the needs of beneficiaries, however, partnerships should collect beneficiary feedback on a regular basis.

- Combine several methods for collecting beneficiary feedback. When choosing a technique for gathering information from beneficiaries, partnerships usually face a trade-off between the reach of the chosen method, the depth and openness of the information it can generate and the duration and frequency with which it can be used. To optimise the supply of information, partnerships should therefore employ several methods at the same time.

- Ensure coverage of relevant sources of information. Partnerships should make sure they receive feedback from the most relevant sources. Depending on the activities of the partnership, this may include, for example, potential beneficiaries who chose not to participate in a programme or it may require the collection of feedback over a longer period of time.

\subsubsection{Summary of standards}

Table 5.3 provides an overview of relevant accountability standards for implementation partnerships.

Table 5.3 Accountability standards for implementation partnerships

\begin{tabular}{|c|c|c|}
\hline $\begin{array}{l}\text { Accountability } \\
\text { principles }\end{array}$ & $\begin{array}{l}\text { Accountability } \\
\text { standards }\end{array}$ & Practical steps \\
\hline \multirow{4}{*}{$\begin{array}{l}\text { Outcome } \\
\text { accountability } \\
\text { through } \\
\text { performance } \\
\text { evaluation }\end{array}$} & \multirow[t]{4}{*}{$\begin{array}{l}\text { Define clear } \\
\text { objectives and } \\
\text { performance targets }\end{array}$} & $\begin{array}{l}\text { Invest significant efforts into the } \\
\text { definition of organisational objectives } \\
\text { and performance indicators }\end{array}$ \\
\hline & & $\begin{array}{l}\text { Demonstrate how performance } \\
\text { indicators will contribute to the } \\
\text { achievement of broader organisational } \\
\text { objectives }\end{array}$ \\
\hline & & $\begin{array}{l}\text { Involve stakeholders in the definition } \\
\text { of goals and targets }\end{array}$ \\
\hline & & $\begin{array}{l}\text { Combine objective and subjective, as } \\
\text { well as quantitative and qualitative } \\
\text { indicators }\end{array}$ \\
\hline
\end{tabular}


Table 5.3 Continued

\begin{tabular}{|c|c|c|}
\hline $\begin{array}{l}\text { Accountability } \\
\text { principles }\end{array}$ & $\begin{array}{l}\text { Accountability } \\
\text { standards }\end{array}$ & Practical steps \\
\hline \multirow{11}{*}{$\begin{array}{l}\text { Outcome } \\
\text { accountability } \\
\text { through the } \\
\text { introduction } \\
\text { of market elements }\end{array}$} & \multirow{3}{*}{$\begin{array}{l}\text { Monitor } \\
\text { performance and } \\
\text { create incentives } \\
\text { for performance } \\
\text { improvement }\end{array}$} & $\begin{array}{l}\text { Plan performance measurement and } \\
\text { start collecting data as early as possible }\end{array}$ \\
\hline & & $\begin{array}{l}\text { Ensure objectivity of data and their } \\
\text { presentation }\end{array}$ \\
\hline & & $\begin{array}{l}\text { Encourage learning by emphasising } \\
\text { positive incentives }\end{array}$ \\
\hline & \multirow{5}{*}{$\begin{array}{l}\text { Outsource suitable } \\
\text { tasks through } \\
\text { competitive bidding } \\
\text { processes }\end{array}$} & $\begin{array}{l}\text { Use competitive bidding processes to } \\
\text { allocate contracts }\end{array}$ \\
\hline & & $\begin{array}{l}\text { Ensure submission of a sufficient } \\
\text { number of bids }\end{array}$ \\
\hline & & $\begin{array}{l}\text { Use a transparent and fair process } \\
\text { for evaluating bids and allocating } \\
\text { contracts }\end{array}$ \\
\hline & & $\begin{array}{l}\text { Define adequate performance indicators } \\
\text { for inclusion in the contracts }\end{array}$ \\
\hline & & $\begin{array}{l}\text { Link contractor performance to } \\
\text { sanctions and incentives }\end{array}$ \\
\hline & \multirow{3}{*}{$\begin{array}{l}\text { Collect beneficiary } \\
\text { feedback to assess } \\
\text { performance }\end{array}$} & $\begin{array}{l}\text { Routinely gather information about } \\
\text { beneficiary satisfaction and preferences }\end{array}$ \\
\hline & & $\begin{array}{l}\text { Combine several methods for } \\
\text { collecting beneficiary feedback }\end{array}$ \\
\hline & & $\begin{array}{l}\text { Ensure coverage of all relevant sources } \\
\text { of information }\end{array}$ \\
\hline
\end{tabular}

\subsection{Standards for information-generating partnerships}

A final group of partnerships identified among the case examples is concerned with the generation of information. Typically, partnerships work with two different kinds of information. One set of partnerships develops factual or technical information and knowledge about certain, often controversial, issue areas. The WCD, for example, invested a major effort into the development of a 'knowledge base' to create a shared understanding among different stakeholder groups on the development effectiveness of dams. ${ }^{115}$

Another set of partnerships generates information with the aim of verifying or certifying to what degree other organisations are complying with specific rules. The MSC, for instance, has created standards for sustainable fisheries. Companies complying with these rules can have their performance verified by independent certification organisations and apply the MSC label to their products. ${ }^{116}$ Similarly, the $4 \mathrm{C}$ initiative contains an element 
of compliance verification. Rather than certifying full compliance with its standards, however, 4C engages organisations in a performance improvement process. Thus the organisations themselves submit information relating to their compliance and draw up improvement plans for problematic areas. Implementation and the systems used for verification are subject to external audit or evaluation. ${ }^{117}$

As these examples show, partnerships rarely pursue the generation of information as their sole or even predominant goal. In the three cases just mentioned, information generation constitutes a major element of the partnerships' work. Even they, however, do not see information generation as a goal in itself but rather as a means to achieve other objectives. Thus, for the WCD, it was an instrument to prepare the ground for consensual rules; MSC uses certification as a lever for increasing compliance with its standards and the $4 \mathrm{C}$ initiative supports its advocacy work by evaluating the implementation and verification of improvement plans.

Irrespective of what broader objectives the partnerships pursue, their information-generating activities are linked to specific accountability requirements. When partnerships create information or knowledge, they do so with the intention that other actors use and rely on that information. In other words, they want to achieve ex-post authorisation by their user groups to produce information on their behalf. Potential users are likely to do that if they feel they can trust the delivered information. To achieve this, partnerships must be able to demonstrate that they are independent and unbiased and that their work stands up to high professional standards.

As illustrated in Figure 5.4, where partnerships focus on the generation of information, they should emphasise accountability for independence and professionalism.

\subsubsection{Transferable accountability practices in universities and the judiciary and guidance from relevant international standards}

Like the other types of partnerships, information-generating partnerships do not have to build their accountability practices in a void. Rather, they can draw lessons from other, functionally similar organisations with more established accountability traditions. As already mentioned, information generation can mean two different things to partnerships. They are usually either concerned with creating factual or technical information and knowledge or with assessing the compliance of other actors with certain standards or rules. These two kinds of information correspond to two different organisational functions. Information-generating partnerships can therefore draw on two types of institutions as role models for their accountability arrangements: universities and the judiciary. Moreover, they can orient themselves along international standards that have been developed for evaluation, compliance verification and accreditation organisations. 


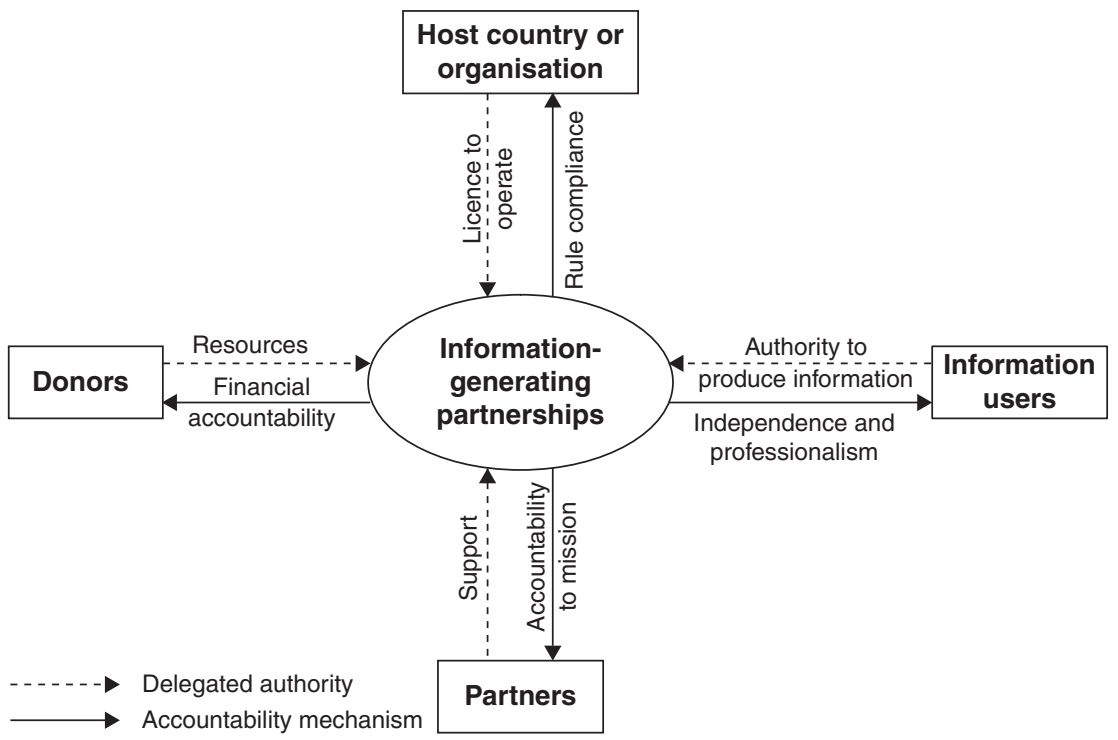

Figure 5.4 Accountability of information-generating partnerships

Universities form the classical institutional context for the creation of knowledge. Since the accountability arrangements of universities have not yet been discussed in this book, they warrant a slightly longer explanation at this stage. A crucial principle informing the governance characteristics of universities is the concept of academic freedom. Academic freedom describes the liberty of students, teachers and academic institutions to pursue their knowledge interests without undue interference. The unhampered search for truth is seen to confer benefits on society as a whole and the principle is closely linked to other precepts of liberal democratic thought. Today, academic freedom is broadly recognised as a normative ideal. ${ }^{118}$ The principle is most strongly protected in Germany, where it enjoys the status of a fundamental right and is enshrined in the constitution: 'Kunst und Wissenschaft, Forschung und Lehre sind frei. Die Freiheit der Lehre entbindet nicht von der Treue zur Verfassung' (Deutscher Bundestag, 2007, Art. 5, § 3). ${ }^{119}$

In the US, to cite another national example, academic freedom is not directly referred to in the constitution. The Supreme Court has, however, consistently interpreted academic freedom as part of the first amendment right to free speech. ${ }^{120}$ Moreover, most US-American academic institutions have endorsed the 1940 Statement of Principles on Academic Freedom and Tenure (American Association of University Professors and Association of American Colleges, 1940). By subscribing to this document, colleges and universities commit to protecting the freedom of their staff in teaching and 
research. Similarly, the academic freedom of university teachers is enshrined in the UK's 1988 Education Reform Act. ${ }^{121}$

To guarantee academic freedom, academic institutions and their staff need to enjoy a certain degree of independence. Two main mechanisms serve to ensure this independence. Firstly, universities are usually conceived as autonomous organisations. This means that even where universities are public institutions, they handle all issues relating to teaching and research internally. ${ }^{122}$ Secondly, the independence of individual university teachers is secured through the institution of tenure. Tenure provides university teachers with a strong, though not unconditional, guarantee of employment. It ensures that they cannot be fired or financially penalised for pursuing a specific line of inquiry in research or teaching. ${ }^{123}$

The accountability arrangements of institutions of higher learning are, however, not only determined by the principle of academic freedom. Another strong concern for universities and their funders is to ensure a high quality of research and teaching. Ongoing mechanisms of quality control can easily undermine the independence of university teachers. Classically, universities have therefore defined very strict professional criteria for applicants to academic posts. These standards introduce formal criteria for academic staff and create strong peer control. To achieve a tenured position, scholars need to pass a range of formal exams, such as Bachelors', Masters' and get doctoral degrees. In addition, professors in the Anglo-American world can only receive tenure after a lengthy period of probation. ${ }^{124}$ Germany and Austria, by contrast, still largely rely on the more formalistic quality assessment provided by an additional postdoctoral qualification, the habilitation. Academic peers play an important role in determining the qualification of their colleagues. Only the academic staff of recognised institutions of higher learning can decide whether individuals pass the formal tests and have the authority to award academic titles. Moreover, committees composed of fellow professors and other staff usually have a strong say in the selection of candidates for academic positions.

Through formal tests and strict appointment procedures, universities guarantee that their teachers and researchers are highly qualified. While these mechanisms are well suited for ensuring high professional standards when appointing new academic staff, they are less apt at vouching for good ongoing quality. Especially tenured professors, who enjoy job and income security, only face soft incentives for maintaining high standards. Many see the lure of prestige and a good reputation as an insufficient means of quality control. Over recent years, an increasing number of countries and universities have therefore increased their efforts at creating mechanisms for ongoing quality assurance. As consequence, promotion, tender and budget allocation decisions do now often take into account the results of performance assessments, based, for example, on student assessments or publication indices. In addition, university rankings focusing on the quality of teaching 
and research create more transparency and competition among institutions of higher learning. ${ }^{125}$

Ongoing mechanisms of quality control have become a popular element of academic accountability. Despite their popularity, however, they are frequently criticised for undermining academic freedom. ${ }^{126}$ There is thus often a tension between the two pillars of accountability in academia, independence and high quality or professionalism.

If independence and professionalism are the two main principles underlying academic accountability, how does this compare to the other possible role model for information-generating partnerships, the judiciary? One author has likened the role of tenured professors to that of judges: 'In relation to tenure the position of the faculty member resembles that of the judge who holds office during good behavior to safeguard his fearlessness and objectivity in the performance of his duties' (Fuchs, 1963, p. 431). Indeed, typical judicial accountability arrangements show important similarities to these principles of academic accountability. In the liberal democratic tradition the judiciary is subject to few external controls. To ensure accountability, the judiciary instead relies mainly on independence and self-control.

Judicial independence entails firstly the formal autonomy of courts and judges. Accordingly, other state organs or external actors have no authority to change and reverse judgements or to interfere with judicial processes. Secondly, special measures serve to undergird the de facto independence of individual judges. Thus, for example, they usually enjoy long or life tenures as well as guaranteed salaries.

Again, independence is not the only relevant element of judicial accountability. To avoid the abuse of authority and ensure professionalism in the work of the judiciary, several mechanisms of self-control are typically in operation. The appeals process provides a bulwark against arbitrary individual decisions and promotes the consistent interpretation and application of legal principles. Compliance verification partnerships also pass judgement over whether or not individuals or organisations comply with specific sets of rules. Unlike the judiciary, however, partnerships mostly deal with voluntary norms and only have access to soft enforcement mechanisms. The institution of a full appeals process is therefore not required of information-generating partnerships.

Other measures adopted in the judiciary focus on the qualification and professionalism of legal staff. Thus most countries have defined very strict professional standards. They typically involve a formal education as well as official entry exams. In most cases, only the best-qualified individuals are eligible for the office of judge.

Both universities and the judiciary, then, stress independence and professionalism or quality control in their accountability arrangements. These principles are also reflected in international standards for inspection, certification and accreditation bodies. Relevant standards include, for example, 
the ISO guide 65 defining general requirements for bodies operating product certification systems (International Organization for Standardization, 1996), ISO standard 17011 for accreditation bodies (International Organization for Standardization, 2004) and ISO standard 19011 for quality and environmental management systems auditing (International Organization for Standardization, 2002). These standards vary in their focus and in some of the details of their recommendations. Overall, however, they all define criteria to safeguard the impartiality and independence, as well as the quality and professionalism of organisations and their staff.

\subsubsection{Accountability for impartiality through independence}

Other actors will only rely on the information generated by partnerships if they trust it. The results of studies or enquiries quickly lose their trustworthiness if suspected to be biased or influenced by specific interests. To create accountability for generating trustworthy information, partnerships must ensure their impartiality and independence.

The partnerships analysed as case examples above have chosen different strategies to guarantee that their information-generating activities are impartial. The WCD was itself ultimately responsible for compiling the report on the development effectiveness of dams. The commission was independent in so far as its findings were not subject to the control of any external party. The commission also enjoyed relative financial independence because it received support from a wide range of donors from all sectors and did not grant these donors any special role in its governance structure. Moreover, the commissioners were chosen to represent a balance among different stakeholder groups, they all enjoyed good international standing and reputation, were appointed for the entire duration of the process and were not financially dependent on their work as commissioners.

The 4C initiative, by contrast, has commissioned independent external organisations with the task of auditing and verifying the compliance of its members. Local verifiers have to be accredited by the Common Code Association. They are independent but can be subject to a systems verification, in turn conducted by an independent external organisation. Moreover, the 4C initiative demands that local verifiers disclose conflicts of interest. Similarly, MSC delegates compliance verification and certification to independent, accredited evaluators. The partnership goes a step further than the $4 \mathrm{C}$ initiative in that it even entrusts the accreditation process to an independent body. Explicitly following ISO standards 17011 and 19011, the agency (Accreditation Services International) accredits certification agencies, which in turn conduct certification assessments.

Which specific standards, then, should both kinds of information-generating partnerships fulfil relating to their impartiality and independence? The experiences of the judiciary and academia as well as the standards defined by ISO suggest that two complementary steps are necessary: Safeguarding the 
institutional independence of the bodies in charge of generating information and ensuring the personal independence of their staff members.

\subsubsection{Ensure institutional independence}

A first step to guarantee the impartiality of the knowledge or assessments developed by partnerships is to grant the bodies responsible for generating information institutional independence. Institutional independence has various dimensions.

Firstly, and most importantly, information-generating bodies should enjoy formal authority over their findings and results. Neither academia, nor the judiciary, for example, enjoys total autonomy. Thus universities are usually either public bodies or they need to be officially accredited. In many countries, moreover, the government formally appoints key academic staff. Similarly, judicial institutions are typically part of the government apparatus, rather than fully independent of it. Courts are public institutions and their judges are most often civil servants that are formally appointed by the government. Yet, both kinds of institutions are formally autonomous in the sense that no other institution has the right to interfere with their substantial results or decisions.

Thus academic freedom entails that universities can choose their focus in teaching and research and that research results are not subject to censorship. ${ }^{127}$ Analogously, the verdicts of courts are considered binding and final and can only be reversed or changed through other judicial decisions. ${ }^{128}$ According to ISO, the same standard should apply to certification bodies. It demands that the certification body be responsible for all decisions relating to the granting, maintaining, extending, suspending and withdrawing of certifications. ${ }^{129}$

Secondly, the financial position of the information-generating body can play an important role. Financial dependence on interested parties can undermine de facto institutional independence. The judiciary and academia, for example, typically receive the overwhelming majority of their resources from the public purse. But at the same time, the principles of judicial independence and academic freedom are grounded in public law. Public financial support can therefore not be tied to conditions relating to the substance of the work of these institutions. ${ }^{130}$ Referring to the same question, the ISO standards stress that the bodies responsible for certification or accreditation should be free from undue commercial, financial or other pressures. They also emphasise that these bodies should describe their sources of income and avoid conflicts of interest. ${ }^{131}$

Finally, especially where complete independence from external interests cannot be guaranteed, institutional impartiality may entail the involvement of a balanced group of stakeholder representatives. In court, for example, judges are expected to be neutral and independent. At the same time, however, both the plaintiff and the defendant are represented through their 
legal counsels. Similarly, the ISO standards and guidelines request at several occasions that processes should be open to the participation of interested stakeholder groups. ${ }^{132}$ Balanced multi-stakeholder arrangements may be particularly relevant for partnerships, which by definition are made up of different interest groups.

Following these examples, information-generating partnerships should adhere to a set of principles to ensure their impartiality and independence:

- Grant information-generating bodies formal and final authority over findings and results. To ensure that no external interests can manipulate the findings of the bodies in charge of generating information, they should have the last word on the subject. Correspondingly, no other institution should have the authority to correct, change, or otherwise amend their results.

- Seek unconditional, diverse and transparent institutional funding. The institutional entities responsible for generating information should enjoy as much financial security as possible. To avoid vulnerability to external pressure, information-generating partnerships should try to receive financial support that is not tied to any substantive results. Preferably, they should rely on diverse funding sources and they should always create maximum transparency concerning their sources of funds.

- Where complete independence from external interests is not possible, seek a balanced multi-stakeholder representation. As an alternative to full independence from external parties, partnerships can foster their impartiality by including a balanced number of representatives of diverse interests in their information-generating committees.

\subsubsection{Foster personal independence}

Institutional independence is only one side of the coin. To create a further bulwark against the manipulation of their findings, key staff members must be protected against external pressures and enjoy personal independence. Several factors can help to strengthen the independent position of key staff members.

Firstly, both academia and the judiciary rely on a high degree of job and income security for professors and judges to increase their immunity against external pressure. In the US, for example, life tenure and guaranteed salaries for judges are even enshrined in the constitution:

The Judges, both of the supreme and inferior Courts, shall hold their Offices during good Behavior, and shall, at stated Times, receive for their Services a Compensation which shall not be diminished during their Continuance in Office.

(United States of America, 1787, Art. III, section 1) $)^{133}$ 
Similarly, the academic world has a tradition of granting life tenure to professors. ${ }^{134}$ The practice here, however, is not handled as strictly as in the judiciary. Following the criticism that tenure can have a negative impact on performance, an increasing number of teachers and researchers work off the tenure track. In addition, tenured professors can often be dismissed on the basis of a faculty decision.

Other organisations may find it difficult to create as much job and income security as the judiciary or academia. They may, for instance, not have the necessary financial security and planning horizon to offer lifetime appointments. In addition, the tasks they pursue may be of shorter duration. ISO has therefore proposed a more general formulation for the employees of accreditation bodies that can be transferred more easily to public policy partnerships:

All accreditation body personnel and committees that could influence the accreditation process shall act objectively and shall be free from any undue commercial, financial and other pressures that could compromise impartiality.

(International Organization for Standardization, 2004, clause 4.3.4.)

A second common step for ensuring the objectivity and independence of individual findings or assessments is to exclude conflicts of interest. Psychological research has found that financial interests create a self-serving bias in the perceptions and assessments of individuals. Interestingly, most test persons were unable to avoid this bias even when it would have been in their best interest to do so. ${ }^{135}$ Institutions valuing objectivity therefore usually adopt practical measures to prevent or deal with conflicts of interest.

In the judiciary, impartiality is a core value. It is symbolised, for example, by Iustitia, the Roman Goddess of Justice, who in many depictions wears a blindfold to indicate that she assesses the merits of each case objectively. To ensure the impartiality of individual judges in practice, two measures are common in the judiciary. Firstly, the principle of impartiality and its practical implications are usually contained in the codes of ethics adopted by courts or professional associations. ${ }^{136}$ Secondly, procedural rules of justice often contain elements protecting the impartiality of judgements. Thus, for example, some legal systems allow for the exclusion of judges from trials when they are reasonably suspected to be biased and others allow for appeals when bias can be demonstrated. ${ }^{137}$

In academia, an important control mechanism for ensuring the impartiality of research findings works on an informal level. Peer control, the public debate of research results and reputation effects create accountability for impartiality. In addition, however, universities, professional organisations and in some cases public authorities have also found more formal ways to 
deal with potential conflicts of interest. Thus the codes of ethics adopted by many professional associations and universities often contain principles relating to conflicts of interest. ${ }^{138}$ In some countries, in addition, many professors enjoy the rank of civil servants. In that case, they are subject to more general regulations for civil servants, which often include the requirements to disclose financial interests or to obtain permission for engaging in additional occupations. ${ }^{139}$

The ISO standards and guidelines, finally, also make frequent reference to and propose concrete rules for dealing with conflicts of interest. Thus, for example, ISO guide 65 requests that certification bodies be free from external pressures and that they do not supply or design products of the type they certify, that they do not provide applicants with advice or consulting services related to the certification process and that they provide no other products or services which could compromise the confidentiality, objectivity and impartiality of their decisions (International Organization for Standardization, 1996, clauses 4.2.n and 4.2.o). Similarly, ISO standard 17011 prescribes that accreditation bodies shall not offer any service that may affect their impartiality and that they shall identify potential conflicts of interest that can arise from their or from related bodies' activities (International Organization for Standardization, 2004, clauses 4.3.6 and 4.3.7).

Thirdly, independence is not only a matter of objective circumstances but also of personal character. John Ferejohn, for example, explicitly introduces this aspect in his discussion of judicial independence: 'Independence, or impartiality, in this sense is a desirable aspect of a judge's character' (Ferejohn, 1999b, p. 353).

It is difficult to establish formal criteria and procedures for assessing an individual's character. In academia and the judiciary, however, the selection or election and appointment processes leave ample space for character considerations. ISO has attempted to define the desirable personal attributes of individuals conducting quality or environmental management systems audits. Accordingly, an auditor should be ethical, open-minded, diplomatic, observant, perceptive, versatile, tenacious, decisive and self-reliant (International Organization for Standardization, 2002, clause 7.2).

In designing their accountability arrangements focusing on the personal independence of key staff members, information-generating partnerships should orient themselves along these examples and observe the following principles:

- Ensure that staff members are free from undue commercial or financial pressures. To achieve this, institutions concerned with generating information can adopt two different strategies. One option is to work with financially independent experts that are not reliant on any income generated through their participation in the partnership. As an alternative, 
partnerships can offer reasonable job and income security for informationgenerating staff. This can involve, for example, fixed-term contracts as well as lump sum payments that are agreed upon at the outset and cannot be reduced based on the content of the results delivered.

- Adopt a written conflict of interest policy and require the disclosure of financial interests. Information-generating bodies should adopt explicit conflict of interest policies, outlining which external activities of key staff members are acceptable and which are not. Moreover, they should require all key personnel to indicate which other interests they hold.

- Appoint individuals of strong, independent character. To enhance the probability that individual researchers and evaluators are personally little susceptible to external pressure, information-generating partnerships can include a list of desired personal attributes in their job descriptions. Moreover, the selection and appointment process should enable a relatively large group of individuals to assess said personal characteristics alongside professional qualifications.

\subsubsection{Accountability for accuracy and quality through professionalism}

For information to be reliable and trustworthy, it does not only need to be unbiased. In addition, it needs to be accurate and of high quality. Next to safeguarding the independence of their information-generating bodies and staff, partnerships should therefore also ensure that they are professional and adhere to high quality standards.

The information-generating partnerships among the case examples rely on several strategies for ensuring the accuracy and quality of their results. For the creation of its knowledge base, the WCD, for example, selected commissioners of high repute representing different stakeholder interests. The commission then collected various kinds of inputs, including case studies of important dam projects, public submissions and debates with involved groups. Moreover, the commission relied on the WCD Forum to test the conclusions it drew from this evidence.

The 4C initiative also employs several parallel mechanisms to ensure the accuracy and quality of its assessment and verification schemes. Independent local verifiers verify the self-assessments submitted by local 4C units. These verifiers must fulfil specific conditions, be listed by the $4 \mathrm{C}$ Secretariat and receive special $4 \mathrm{C}$ training. ${ }^{140}$ In addition, local verifications can be subject to a systems verification. These verifications are conducted by 'internationally recognised bodies' appointed by the executive board of the $4 \mathrm{C}$ association. The initiative also has several channels for dealing with disputes arising in the context of verification. Potential complaints are dealt with by the $4 \mathrm{C}$ secretariat, by the mediation board or by the independent ombudsman. 
In a similar vein, MSC has various mechanisms in place to ensure the accuracy and quality of its certification processes. All certification bodies have to be accredited by an independent accrediting agency contracted by MSC. Moreover, MSC has defined standards relating to the professional expertise each assessment team must include. ${ }^{141}$ In parallel to these standards, stakeholders and interested parties are given several opportunities to comment on the certification process. ${ }^{142}$ If they are not satisfied with the final assessment, they can also lodge a formal objection. The certification body itself hears objections, but appeals to the MSC Objections Panel are also possible.

The practice of these information-generation partnerships, the experiences of the judiciary and academia and the standards defined by ISO suggest that partnerships should take two main steps to ensure that their results are accurate and of good quality: they should entrust the task of generating information to experts with relevant professional qualifications and they should create avenues for verifying results.

\subsubsection{Recruit experts with formal qualification and good reputation}

A crucial measure for fostering trust in a partnership's findings is to ensure that the individuals entrusted with generating information have appropriate professional qualifications and enjoy a good reputation.

Academia and the judiciary rely on similar practical steps to guarantee the professionalism of their staff. Both use specialised higher education programmes and professional training combined with official admissions tests as formal selection criteria. Thus only individuals that have successfully completed the relevant university education and that have passed the respective bar or state exams are eligible as candidates. In many cases, the ensuing selection and appointment process introduces an additional element of peer or popular evaluation. In academia, for example, the faculty usually plays a strong role in assessing and ranking potential new colleagues. In the judiciary, only some countries include peer or popular assessments in their selection procedures. In the US, for example, many judges are appointed following popular elections. Other judges are selected based on merit. In this case, a nomination committee comprising fellow lawyers as well as non-lawyers usually nominates them. ${ }^{143}$

The judiciary and different academic subjects each have their own dedicated higher education programmes as well as specialised qualification exams. Other institutions concerned with producing knowledge or assessing behaviour may be younger and may concentrate on much smaller thematic niches. For many, it is therefore difficult to resort to equally formalised and standardised selection practices. Instead, however, they can provide clear definitions of the formal qualifications and practical experiences they require of candidates. And they can offer additional specialised training to their staff. 
ISO, for example, has defined such standards for quality and environmental management systems auditors. ${ }^{144}$ In addition, ISO requires that auditors demonstrate their continual professional development and that they undergo regular evaluation.

To achieve similar levels of professionalism to the institutions discussed above, the partnership or independent bodies entrusted with generating information should comply with the following standards:

- Define necessary professional qualifications in terms of skills, education, work experience and training. For the recruitment of their researchers, evaluators or certifiers, information-generating partnerships should clearly outline formal qualification requirements. These should include a description of necessary generic skills as well as concrete conditions concerning the applicant's formal education, training and years and type of work experience.

- Include elements of peer or stakeholder assessment in the selection process of staff members. In addition to meeting formal criteria, it is important that candidates demonstrate the quality of their work. A proven practical way of achieving this is to involve peers or a broader group of stakeholder representatives in the nomination and selection of applicants.

- Where tasks are very specific, provide staff members with targeted training. Especially in partnerships engaged in compliance verification and certification, it is important that evaluators interpret and apply criteria consistently and follow comparable assessment strategies. To ensure staff members are able to do that, specialised training may be necessary.

- Encourage continuous professional development and periodically evaluate staff competences. Finally, information-generating partnerships should also be concerned with further developing the competences and experiences of their staff. They should therefore invest in the creation of professional development strategies. Regular evaluations of staff skills can, moreover, help to identify competence gaps and training needs.

\subsubsection{Create possibilities for verifying or disputing results}

Even the best-qualified and independent researchers and assessors can err in their analyses and judgements. A final important step for increasing the trustworthiness of the generated information therefore involves creating avenues for debating, disputing or verifying results.

In the academic world, open debate is a fundamental principle contributing to the advancement of science. The academic community is so big and structured in such a way that there are usually one or several groups of researchers focusing on the same or very similar topics. In this environment, new findings are subject to intense scrutiny and debate. And, without any formal rules governing this process, only widely accepted research 
results enter the canon of established knowledge. With the emergence of new approaches or contrary research results, however, even 'established knowledge' can be challenged at any time. Academia also acknowledges the importance of peer opinions in a more structured way. Thus, for example, the most respected scientific journals tend to be those involving a peerreview process. The reputation and influence of individual researchers, in turn, depends in part on how many articles they manage to publish in recognised journals.

A much more formal approach to debating or verifying results is dominant in the judiciary. Most judicial systems include a hierarchy of courts. Parties who feel wronged by a judgement can appeal to and have their case reheard by a court at a higher level. ${ }^{145}$ Only the decisions of the highest court cannot be challenged within the judicial system. Appeals processes have been recognised as very effective means of recognising and rectifying judicial mistakes. ${ }^{146}$

For organisations involved in certification and accreditation activities at the international level, ISO has defined relevant standards. Accordingly, these organisations should have a - preferably independent - person or body to deal with complaints, appeals or disputes. The processes should include a decision on the validity of the appeal, the taking of appropriate action and a public documentation of all appeals, decisions and corresponding actions. ${ }^{147}$

For information-generating partnerships, these practices and rules can be translated into the following standards:

- Develop a procedure for soliciting public comments on drafts. Information generating partnerships should make copies of their preliminary findings available to the public. They should also adopt a formal procedure for dealing with comments received.

- Encourage and facilitate open debate about findings and results. Especially partnerships engaged in the creation of knowledge should actively promote debate on their findings. Depending on the context of the initiative, this may require holding local or regional discussion fora or establishing electronic debate platforms. Formal peer-review processes can further enhance the credibility of their results.

- Create a formal complaints or appeals processes. Partnerships engaged in verifying or certifying compliance with certain standards should, moreover, have formal and institutionalised complaints and appeals processes. This involves having a designated, preferably independent, person or body for hearing complaints and a clear process for deciding and taking action on appeals. In addition, the process should be made transparent by maintaining and publishing records of all complaints and appeals, as well as the corresponding decisions and actions. 


\subsubsection{Summary of standards}

Table 5.4 provides an overview of relevant accountability standards for information-generating partnerships.

Table 5.4 Accountability standards for information-generating partnerships

\begin{tabular}{|c|c|c|}
\hline $\begin{array}{l}\text { Accountability } \\
\text { principles }\end{array}$ & $\begin{array}{l}\text { Accountability } \\
\text { standards }\end{array}$ & Practical steps \\
\hline \multirow[t]{6}{*}{$\begin{array}{l}\text { Accountability for } \\
\text { impartiality through } \\
\text { independence }\end{array}$} & \multirow[t]{3}{*}{$\begin{array}{l}\text { Ensure institutional } \\
\text { independence }\end{array}$} & $\begin{array}{l}\text { Grant information-generating bodies } \\
\text { formal and final authority over their } \\
\text { findings and results }\end{array}$ \\
\hline & & $\begin{array}{l}\text { Seek unconditional, diverse and } \\
\text { transparent financial support }\end{array}$ \\
\hline & & $\begin{array}{l}\text { Where complete independence from } \\
\text { external interests is not possible, seek } \\
\text { balanced stakeholder representation }\end{array}$ \\
\hline & \multirow[t]{3}{*}{$\begin{array}{l}\text { Foster personal } \\
\text { independence of key } \\
\text { staff }\end{array}$} & $\begin{array}{l}\text { Ensure that staff members are free } \\
\text { from undue commercial and financial } \\
\text { pressures }\end{array}$ \\
\hline & & $\begin{array}{l}\text { Adopt a conflict of interest policy } \\
\text { and require the disclosure of financial } \\
\text { interests }\end{array}$ \\
\hline & & $\begin{array}{l}\text { Appoint individuals of strong, } \\
\text { independent character }\end{array}$ \\
\hline \multirow[t]{7}{*}{$\begin{array}{l}\text { Accountability } \\
\text { for accuracy and } \\
\text { quality through } \\
\text { professionalism }\end{array}$} & \multirow[t]{4}{*}{$\begin{array}{l}\text { Recruit experts } \\
\text { with formal } \\
\text { qualifications and } \\
\text { good reputations }\end{array}$} & $\begin{array}{l}\text { Define necessary professional } \\
\text { qualifications in terms of skills, } \\
\text { education, work experience and } \\
\text { training }\end{array}$ \\
\hline & & $\begin{array}{l}\text { Include elements of peer or stakeholder } \\
\text { assessment in the selection process for } \\
\text { staff members }\end{array}$ \\
\hline & & $\begin{array}{l}\text { Where tasks are very specific, provide } \\
\text { staff members with targeted training }\end{array}$ \\
\hline & & $\begin{array}{l}\text { Encourage continuous professional } \\
\text { development and periodically evaluate } \\
\text { staff competences }\end{array}$ \\
\hline & \multirow{3}{*}{$\begin{array}{l}\text { Create possibilities } \\
\text { for debating, } \\
\text { disputing and } \\
\text { verifying results }\end{array}$} & $\begin{array}{l}\text { Develop a procedure for soliciting } \\
\text { public comments on drafts }\end{array}$ \\
\hline & & $\begin{array}{l}\text { Encourage and facilitate open debate } \\
\text { about findings and results (especially } \\
\text { for partnerships generating knowledge) }\end{array}$ \\
\hline & & $\begin{array}{l}\text { Create a formal complaints or appeals } \\
\text { process (especially for partnerships } \\
\text { verifying compliance) }\end{array}$ \\
\hline
\end{tabular}

